\title{
2 Manuscripts Written by Students
}

As with the multiple-text booklets examined in the previous chapter, the overall majority of Dunhuang manuscripts have Buddhist content. Although other types of texts constitute a smaller portion of the corpus, together they are still sizeable in volume. Among this body of non-Buddhist material, manuscripts with colophons written by students studying at local monasteries present a fascinating subset. Despite their association with monasteries, the students had secular names and chiefly copied secular texts. Most of the specific details about them derive from the colophons they appended to the texts they copied. The students produced the manuscripts over a timespan that falls within the range of the Guiyijun period. The typological similarities of these manuscripts justify treating them as a unique group which, as was the case with the multiple-text manuscripts in the previous chapter, may offer insights into the lives and activities of a specific segment of local society.

From the 1970s onward, scholars of Dunhuang and medieval China have examined these manuscripts, authoring a variety of excellent studies. In contradistinction to earlier approaches focusing on the history of education and its institutions, the current chapter aims to examine how students produced the manuscripts and continued using them long after the initial act of production. Crucial to the methodology applied here is the analysis of the visual characteristics of the scrolls, especially their layout and marginalia. As before, my contention is that the examination of non-textual aspects alongside textual ones will provide further insights into the specific circumstances that shaped the manuscripts before being deposited in the library cave.

\subsection{Former scholarship}

In the early days of Dunhuang studies, the scrolls featuring student colophons attracted little attention. Occasional references tended to discuss individual examples along with other types of colophons, without attempting a comprehensive analysis. Among the first scholars to mention poems written by Dunhuang students was the celebrated philosopher and scholar Hu Shih 胡適 (i.e. Hu Shi, 1891-1962), who cited two compositions he termed yuanshi 怨詩 ('poems of lament'). Taking them at face value-as expressions of sentiments 
associated with student life-he wrote that he could commiserate with the laments these young authors expressed from a distance of a thousand years. ${ }^{178}$

Paradoxically, the biggest impetus for the study of the Dunhuang manuscripts written by students came from a manuscript discovered not in Dunhuang but Turfan. The discovery happened in 1969, at the height of the Cultural Revolution (1966-1976), during the excavation of Tomb 363 of the Astana cemetery near Turfan. The scroll in question contained Zheng Xuan's 鄭玄 (127-200) commentary to the Lunyu 論語 (Analects), commonly known as the Lunyu Zheng shi zhu 論語鄭氏注. According to the colophon, the text was copied in 710 by a twelve-year old student called Bu Tianshou 卜天壽. ${ }^{179}$ Following its discovery, Guo Moruo 郭沫若 (1892-1978), the famous writer and scholar, Mao's most favoured intellectual and president of the Chinese Academy of Sciences, wrote a brief introduction in which he praised the literary quality of the poems. He also commented on the abundance of non-standard character variants (biezi 別字). ${ }^{180}$ The discovery generated a flurry of scholarship on the pages of the academic journals Kaogu 考古 and Wenwu 文物, with scholars correcting some of Guo's readings and discussing the problem of phonetic variants. ${ }^{181}$ In 1972, the Japanese publisher Heibonsha issued a volume with a full set of photographs (including colour prints), thereby making the scroll accessible to all. ${ }^{182}$ The book also included photographs of four Lunyu manuscripts from Dunhuang, as well as Japanese translations of the newly published Chinese studies on the manu-

178 Hu Shi 1937.

179 Technically, he was twelve sui 歲, which would make him eleven years old.

180 Guo Moruo 1972a. Guo's paper appeared in the first issue of Kaogu that year, shortly before the publication of the official excavation report of the Xinjiang Museum (Xinjiang Weiwu'er zizhiqu bowuguan 1972; on the manuscript specifically, see also Wenwu chubanshe 1972), making him the first to write about the manuscript. In the same issue of Kaogu, as part of a survey of archaeological discoveries from the ongoing Cultural Revolution, Xia Nai 夏鼎 (1972, 36-37) also briefly described the manuscript and published a photograph. Other studies addressed the textual aspects of the manuscript (Zhongguo kexueyuan kaogu yanjiusuo ziliaoshi 1972) and its handwriting (Han Guopan 1973).

181 Long Hui 1972a and 1972b.

182 Tei Gen 1972. A few years later, Kanaya Osamu 金谷治 also published a collection of Lunyu Zheng shi zhu manuscripts from Dunhuang and Turfan (Kanaya 1978). A similar collection of Lunyu Zheng shi zhu manuscripts by a Chinese scholar was Wang Su 1991; see also the additional comments in Rong Xinjiang 1993. On the history of the text, including relevant manuscript evidence, see Makeham 1997; on its significance in education in the Tang period, see Simson 2009, 220-226. 
script. ${ }^{183}$ In the 'Preface', Guo Moruo makes the point that Bu Tianshou's copy of the Lunyu illustrates that at the beginning of the eighth century, the cultural level in the Western Regions was essentially of the same calibre as that of Central China. ${ }^{184}$

The study of the Astana manuscript re-focused scholarly attention on comparable manuscripts from Dunhuang. In 1973, Ogawa Kan'ichi 小川貫式 published two papers in which he examined student colophons from Dunhuang as a coherent group of material. ${ }^{185} \mathrm{He}$ saw that the gradual availability of the main collections of Dunhuang manuscripts in print or microfilm had made it possible to progress from the initial tasks of cataloguing and conducting case studies, to more comprehensive analyses involving larger groups of manuscripts. Noting that the student manuscripts dated from the Guiyijun period, he divided them into two groups: those from the period of the Zhang family's rule (848-914) and those of the Cao family's rule (914-1030). ${ }^{186}$ He listed over fifty manuscripts with such colophons and observed that students identified themselves as belonging to particular monasteries primarily during the tenth century and not earlier. He also directed attention to colophons written by members of the two ruling families. Ogawa was the first to explore student manuscripts from Dunhuang in detail and draw up an initial inventory upon which subsequent scholars could depend.

An important English-language study was Victor Mair's 1981 catalogue of Dunhuang manuscripts written by lay students. ${ }^{187}$ This was a basic description of nearly 600 manuscripts the author judged to have been produced by students, including those with student colophons. Whenever available, Mair transcribed and translated the colophons and added brief comments on links to other manuscripts, the quality of handwriting, corrections, punctuation and other palaeographic peculiarities. This catalogue was a major step in delineating the corpus of manuscripts related to students. It presents manuscript data in a useful arrangement and contains insights of great value to anyone working on Dunhuang manuscripts.

183 Guo Moruo wrote a preface, which appears in the volume in both Chinese (i.e. Guo's calligraphy) and Japanese.

184 Kanaya 1978, 8.

185 Ogawa 1973a and 1973b.

186 The closing date of 1030 derived from Pelliot's now discredited theory that the library cave had been sealed on the eve of the Tangut conquest as a means for preserving the manuscripts. 187 Mair 1981. A digital version of this catalogue is now also available through the IDP website (http://idp.bl.uk). 
In 1986, the Taiwanese historian Kao Ming-shih 高明士 wrote a thorough overview of Tang education in Dunhuang, in which he also examined the colophons written by students. He divided the Tang dynasty in Dunhuang into three periods: 1. High Tang (618-787); 2. Tibetan period (787-848); and 3. Late Tang (848-907). He discussed the educational activities of local monasteries within the third period, under the category of private schools. ${ }^{188}$

Around the same time, Li Zhengyu 李正宇 published two influential papers related to the manuscripts written by students. The first had a wider focus and looked at schools in Dunhuang in general, from early Tang to the end of the Guiyijun period. ${ }^{189}$ In this group, students studying at local monasteries were merely one category among those from various types of schools, including provincial and county-level ones. ${ }^{190}$ The second paper focused specifically on student colophons, gathering all available examples and arranging them in chronological order. ${ }^{191} \mathrm{He}$ identified 144 colophons, observing that some were not genuine. He divided the colophons into three groups: those that were dated unambiguously using reign marks; dated using the cyclical format; or undated. In total, he found that 72 colophons were dated unambiguously, providing a substantial sample base for comparison. Of the cyclical dates, some employed the sexagecimal cycle and others the duodecimal corresponding to the animal signs of the zodiac. Of the undated manuscripts, some may have originally had colophons now lost or illegible due to damage. ${ }^{192} \mathrm{Li}$ Zhengyu's inventory remains useful to this day, even though now it is possible to improve on the accuracy of some of the dates.

Shortly after this, in a study devoted to the role of Buddhism in education during the Tang period, Erik Zürcher discussed manuscripts written by students. ${ }^{193}$ After providing an extensive overview of evidence concerning Buddhist education in transmitted sources, Zürcher turned to the Dunhuang manuscripts

188 Gao Mingshi 1986. Of course, one of the arguments of the present book is that the concept of Late Tang was not directly applicable to Dunhuang. On the Tang-dynasty phenomenon of studying at Buddhist monasteries, as seen in literary sources, see Yan Gengwang 1969.

189 Li Zhengyu 1986a.

190 Unfortunately, very few colophons explicitly identify students as belonging to any of these types of schools, thus providing accurate statistics is difficult. Essentially, only one or two colophons survive for each type.

191 Li Zhengyu 1987.

192 As the manuscripts lay hidden inside a cave for a millennium, any such damage would have occurred before being stored in the cave and could not have been caused by wear and tear during the subsequent centuries.

193 Zürcher 1989. 
to examine the kinds of texts students copied while they studied in monasteries. Calling attention to the writing exercises on the verso of manuscripts, he hypothesised that some of the students were merely five or six years old. He cited a series of examples in which the master wrote a text such as the Qianziwen (Thousand Character Text) horizontally across the top of the page and the student copied each character in vertical columns over an entire line. This type of practice probably occurred during the earliest stage of education, while primers would have been copied at a slightly more advanced level. Zürcher also discussed the group of manuscripts with student colophons and emphasised that the colophons were almost exclusively attached to secular texts, despite the fact that the students often identified themselves as belonging to specific monasteries. Continuing Zürcher's approach, a more recent overview on Tang education in the light of the Dunhuang and Turfan manuscripts has been provided by Wojciech Simson. ${ }^{194}$

In Japan, from approximately the turn of this century, Itō Mieko 伊藤美重子 has dedicated a series of studies to Dunhuang manuscripts written by students. ${ }^{195}$ Her primary focus has been on educational texts but also on student poems, eventually leading to a monograph on school education in Dunhuang as seen through the manuscripts. ${ }^{196}$ Although the subject of the book is broader, the first chapter is a systematic analysis of student colophons and relevant manuscripts. At the core of the chapter is a carefully compiled inventory of colophons, by far the most comprehensive and detailed to this day. It consists of three different lists, the first of which has six categories based on the type of main text in the manuscript (e.g. Confucian or Daoist classics and the Qianziwen, vernacular literature, didactic primers). The first list encompasses manuscripts from any period, provided the colophon states that a student copied the text. The second list contains colophons from the Zhang family's rule over Dunhuang in chronological order, and the third, those from the period of the Cao family's rule. The lists provide an efficient and convenient tool for studying this body of material. In a separate chapter, Itō discusses the poems written by students and provides a full transcription of the entire corpus.

Other contributions focused specifically on student poems. In his 1994 study of Dunhuang poems, Xiang Chu 項楚 transcribed and organised these texts as part of a chapter on folk poetry. ${ }^{197} \mathrm{Xu}$ Jun's 徐俊 important 1995 study contended that the poems were not necessarily the result of the students' liter-

\footnotetext{
194 Simson 2009.

195 E.g. Itō 2001 and 2007a.

196 Itō $2007 \mathrm{~b}$ and 2008.

197 Xiang Chu 1993, 210-220.
} 
ary creativity, but were part of a shared repertoire of folk poems or songs. ${ }^{198}$ By contrast, Yang Xiuqing 楊秀清 viewed the poems as an opportunity to gain a glimpse of the students' lives in Dunhuang, an aspect neglected by earlier scholarship. ${ }^{199} \mathrm{Zhu}$ Fengyu’s 朱鳳玉 more recent study differentiates between the poems students composed themselves and those they merely copied. ${ }^{200}$

A great deal more research exists on educational texts in Dunhuang, but it focuses primarily on the texts, rather than the social and educational setting of the learning experience. The most important of which is by Zheng Acai 鄭阿財 and Zhu Fengyu, a comprehensive study of educational texts from Dunhuang. ${ }^{201}$ In addition, extensive research is also available on individual primers, such as the Qianziwen, ${ }^{202}$ Taigong jiajiao 太公家教 (Family Instructions of the Grand Duke), ${ }^{203}$ Kaimeng yaoxun (Essential Teachings for Beginners), ${ }^{204}$ Kongzi Xiang Tuo xiangwen shu (Discussion of Confucius with Xiang Tuo), ${ }^{205}$ Zachao 雜抄 (Miscellaneous Jottings) and many others. ${ }^{206}$ In contrast with such text-oriented studies of primers and poems, the purpose here is to examine the manuscripts themselves and document the physical and codicological attributes they have in common. The goal therein is to demonstrate is that by viewing them together as a group, such attributes may offer additional insights into the circumstances of their production. ${ }^{207}$

$198 \mathrm{Xu}$ Jun 1994; cf. Xu Jun 2000.

199 Yang Xiuqing 1999.

200 Zhu Fengyu 2007.

201 Zheng and Zhu 2002. This work should be the first point of reference on medieval primers.

202 On the Dunhuang Qianziwen, see Zhang Nali 2001, 2002a and 2002c, Zhang Xinpeng 2008, Chen Ziqin 2015 and Nugent 2018.

203 On the Taigong jiajiao, see Demiéville 1982, Gao Guofan 1984, Wang Fanzhou 1986, Zhou Fengwu 1986, Liu Anzhi 2009, Zhang Xinpeng 2010 and 2012. For a recent edition of this text, including a translation into Japanese, see Yōgaku no kai 2009.

204 On the Kaimeng yaoxun, see Wang Fanzhou 2000 and Zhang Xinpeng 2013.

205 On the Kongzi Xiang Tuo xiangwen shu, see Soymié 1954, Zhang Hongxun 1985 and Zheng Acai 1993.

206 Although its title suggests a generic reference to miscellaneous notes, the Zachao in Dunhuang was a title of a specific text that survives in 13 different manuscripts. See Naba 1942, Zhou Yiliang 1948, Takata 1983, Zhu Fengyu 1988 and Zheng and Zhu 2002, 165-194.

207 In this respect, Christopher Nugent's (2010) book on the production and circulation of manuscripts with poetry is directly relevant to the approach implemented here, even if it does not specifically discuss the manuscripts in question as the work of students. See also Galambos 2015b. 


\subsection{The colophons}

Not all manuscripts written by students have colophons. Often the colophon is missing due to damage to the manuscript, but occasionally the individual copying the text just did not write one. In other instances, the colophon does not identify the individual copying as a student. The designation 'student colophons' used in this chapter is a translation of the Chinese term xuelang tiji 學郎 題記, used in modern scholarship as a reference to colophons in which students have identified themselves as xuelang 學郎, xueshilang 學士郎 (also written 學 仕郎 or 學使郎) or, less frequently, xuesheng 學生 or xueshenglang 學生郎. A concrete example of such colophons from the Guiyijun period is in manuscript P.2825, in which the main text on the recto is the primer Taigong jiajiao. As usu$\mathrm{al}$, the colophon appears at the end of the scroll, following the end title of the main text: ${ }^{208}$

\section{大中四年庚午正月十五日學生宋文顯讀＼cjkstart安文德寫}

Read aloud by the student Song Wenxian and copied by An Wende on the fifteenth day of the first month of the gengwu year, the fourth of the Dazhong reign (850).

In this colophon Song Wenxian identifies himself as a student (xuesheng 學生), although An Wende was probably a student too. One possible scenario may have been a student reading the text to a peer who wrote it down either after hearing it or copied it from a previous copy. In either case, the manuscript's production had clearly been part of an exercise or an assessment. The second part of the colophon referring to An Wende stands slightly apart and is written in larger characters, possibly by a different hand. The same hand may have written the character $d u$ 讀 ('to read') immediately before the hiatus. Therefore, these five characters (i.e. 讀 安文德寫) may represent a later addition. Indeed, the first part of the colophon (minus the character 讀) is complete on its own and the second part (along with the character 讀) may have served as an addendum aiming to clarify the division of labour between the two students.

Another colophon, from a year later (i.e. 851), in manuscript S.705 states that the same two students produced a copy of the Kaimeng yaoxun. The hand in the two colophons appears to be the same. This colophon in the second manuscript reads as follows: 


\section{大中五年辛未三月廿三日學生宋文獻誦安文德寫}

Recited by the student Song Wenxian and copied by An Wende on the twenty-third day of the third month of the xinwei year, the fifth year of the Dazhong reign (851). ${ }^{209}$

Once again, there appears to be a small gap before the name An Wende, but it is barely noticeable. The last syllable in the name of Song Wenxian is written with a different character (獻, LMC xian `vs. 顯, LMC xjian`) but the context leaves little doubt it was the same student. If anything, the different way of writing his name shows that as long as the sound was approximately similar (if not identical), it was possible to write one's name with alternative characters. It is also possible that An Wende wrote his peer's name and was not certain how to write it correctly, for he had only heard the name and had not seen it in written form. Furthermore, the verb describing Song Wenxian's contribution here is song 誦 ('to recite'), but it is clear that in both cases the text is being read aloud and the other student is writing or copying the text. As the two manuscripts are only a year apart and were produced using the same division of labour, we can see that the two students collaborated on two or more occasions.

Another example of a student's colophon is the one at the end of a copy of the Qin fu yin 秦婦吟 (Lament of the Lady of Qin) of Wei Zhuang 韋莊 (ca. 836910) in manuscript P.3381. ${ }^{210}$ The colophon appears to be in the same, relatively confident hand as the main text and the end title. It reads as follows:

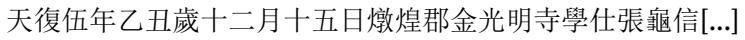

[Copied] on the fifteenth day of the twelfth month of the yichou year, the fifth of the Tianfu reign (905), by Zhang Guixin, student of the Jinguangming Monastery in Dunhuang commandery.

The end of the name Zhang Guixin is partially missing, but the character 信 remains recognisable. The verb at the end of the colophon is also missing, so the lower edge of the scroll may have been trimmed or damaged. In its current form the edge is uneven and shows signs of wear, thus the damage must have occurred before the scroll had been deposited in the cave library at the beginning of the eleventh century. Zhang Guixin identified himself using the term xueshi 學仕, which is possibly an abbreviation of xueshilang and may not neces-

209 Cf. Giles 1939, 1025.

210 On the Qin fu yin, see Chen Yinque 1936, Nugent 2010, 31-65 and Tian Weiwei 2014. 
sarily indicate a different type of student. ${ }^{211}$ The colophon states that Zhang was from the Jinguangming (Golden Light) Monastery 金光明寺, and this is in fact the earliest dated colophon associating a student with this monastery. A similar colophon from fourteen years later appears at the end of another copy of the Qin fu yin in manuscript S.692, written in a much less skilled hand. Fig. 25 shows the end of the scroll with a white arrow marking the line with the colophon. The colophon reads:

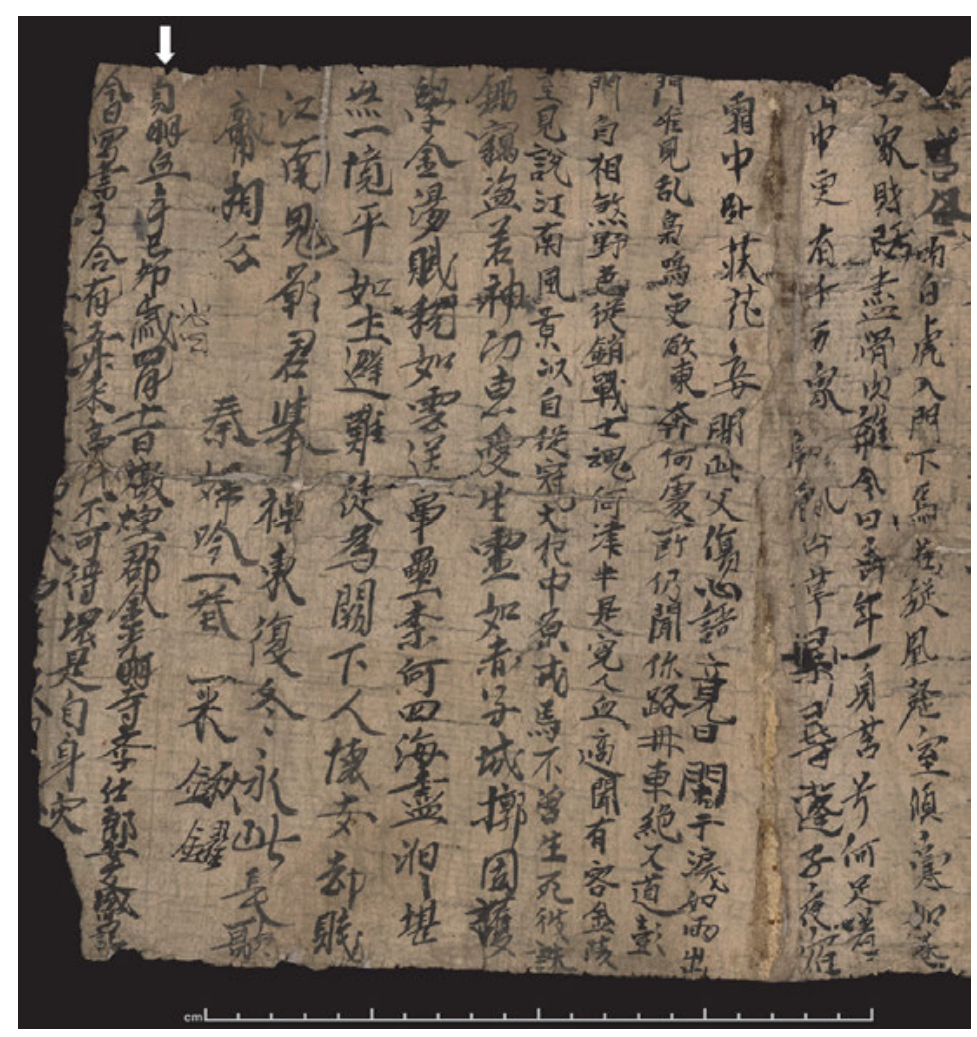

Fig. 25: Section of the recto of S.692, showing the end of the Qin fu yin and the colophon $(26.9 \times 141.2 \mathrm{~cm}$; The British Library)

211 The second character is not clear in the manuscript and is perhaps more similar to the character 什. This, however, would be somewhat problematic phonetically as 什 (LMC ship) is an entering tone character and its pronunciation was quite different from 仕 (LMC shṛ̂) or 士 (LMC sfrị). Just as importantly, such reading is completely unattested among the variations of the word 'student' in this group of manuscripts. 
貞明伍年己卯歲四月十一日燉煌郡金光明寺學仕郎安友盛寫記。

Record of copying on the eleventh day of the fourth month of the jimao year, the fifth of the Zhenming reign period (919), by An Yousheng, student of the Jinguangming Monastery in Dunhuang commandery. ${ }^{212}$

It is clear that not only is the main text the same but the colophon itself is very similar - expressly identifying the student as one of the Jinguangming Monastery in Dunhuang commandery. ${ }^{213}$ Other xuelang manuscripts from roughly the same time feature a variety of other texts, but never the Qin fu yin. Indeed, of the four copies of the Qin fu yin bearing student colophons, only these two name the student as belonging to a monastery, and in both cases it is the Jinguangming Monastery. This does not mean, of course, that the students in each monastery copied the same texts but it shows that at least in this period the Qin fu yin was part of the curriculum at the Jinguangming Monastery. Other texts students copied in this monastery are the Lunyu (S.3011, dated 858), Li Ling Su Wu wanghuan shu 李陵蘇武往還書 (Letter Exchange between Li Ling and $\mathrm{Su} \mathrm{Wu}$; P.3692, dated 922) and the Yanzi fu 䳡子賦 (Rhapsody on the Swallow; P.3757, undated). ${ }^{214}$

The term for the student here is xueshilang 學仕郎, which corroborates the reading of xueshi in P.3381 above, as an abbreviation of it, and proves that the second character should indeed be read as 仕. Following immediately after the colophon is a student poem (see below) followed by another poem that has been torn off. Remnants of a few characters from the missing line can still be made out but are too fragmentary to identify the poem.

It is also noteworthy that the student's surname is An, identifying him to be of Sogdian background. This was by no means unusual and even within student

212 Cf. translation of colophon in Giles 1940, 325.

213 Dunhuang/Shazhou is sometimes referred to as a prefecture (zhou 州) and sometimes as a commandery (jun 郡), reflecting the official designation of the region. In 619, the Tang administration set up Guazhou 瓜州 prefecture with a prefectural seat in Dunhuang; in 622, it was renamed Western Shazhou 西沙州 prefecture; in 633, the word 'Western' was dropped; during 742-758, the region was named Dunhuang commandery 敦煌郡; and in 758, it was named Shazhou prefecture once more; see Li Zhengyu 1986a, 39.

214 On the Yanzi fu, see Jian Tao 1986 and Huang Zheng 2003. For the text of the surviving versions of the text, see Pan Chonggui 1994, 1135-1167. Both Hans van Ess (2003, 611) and Valérie Lavoix $(2014,182)$ note the similarities between the Yanzi fu and the Han-dynasty Shenwu fu 神烏傅(賦) excavated in 1993 in Yinwan 尹灣, Jiangsu Province. For the Lunyu manuscripts from Dunhuang, see Kanaya 1978, Wang Su 1984 and 1991, Li Fang 1998, Zhang Yongquan 2008, v. 4, 1437-1881 and Hao Chunwen 2014. 
colophons there are a number of individuals whose names signify Sogdian origin (e.g. An Wende, Kang [...]yuan 康 $\square$ 遠, Shi Qingtong 石慶通). ${ }^{215}$ In contrast, Zhang Guixin in P.3381 is a typical Chinese surname, the most common in the Dunhuang region of the period. ${ }^{216}$ This attests to the complexity, in cultural and ethnic terms, of the local population during the Guiyijun period, especially its literate segment. The degree to which segments of the Central Asian population were integrated is evidenced by the fact that students of a Sogdian background were copying Chinese literary texts alongside their Chinese peers.

The above examples are merely three of over a hundred and fifty colophons written by students. Although they contain numerous shared features that justify placing them in the same group, they also exhibit considerable variation. Nonetheless, the variable information mainly pertains to the students' particular circumstances, whereas the colophons demonstrate a relatively formulaic structure. Focusing on their common characteristics, it is possible to outline the basic structure they tend to, even though individual examples may deviate:

\section{(i) Date}

The date may include the reign title and the year, which convert unambiguously to the Gregorian calendar we use today, or a combination of cyclical signs which repeat every sixty or twelve years. Often the cyclical date supplements the reign title, which, in theory, provides an added level of accuracy. The two, however, do not always match. As for the general chronological framework, almost all unambiguous dates fall within the Guiyijun period. In Li Zhengyu's catalogue of student manuscripts, only three items with absolute dates come from before this period. Of these, the first is P.3274, an annotated copy of the Xiaojing 孝經 from 742; the second is Bu Tianshou's 759 copy of the Lunyu from Astana (i.e. not from Dunhuang); and the third is a scroll from 767 most likely bearing a forged colophon. ${ }^{217}$ Therefore, only one Dunhuang manuscript may pre-date the Guiyijun period.

Of the manuscripts with dates given in the cyclic format, Li Zhengyu lists only one from before the end of the Tibetan period. This is manuscript BD06258

215 For a summary of Sogdian personal names, see Yoshida 2006. See also the discussion in Chapter Four of this book.

216 Dohi 2015, 6 shows that out of the 19,765 occurrences of full names from the Guiyijun period 2,789 (i.e. 14\%) contained the surname Zhang. The next most common surname was Wang 王 with 1,232 occurrences, numbering less than half of those with the surname Zhang.

217 Li Zhengyu 1987, 27. 
from the xinchou 辛丑 year, which Li claims refers to $821 .{ }^{218}$ Yet, as Zhang Xiuqing 張秀清 demonstrates, the cyclical signs probably denote 881, meaning this manuscript in fact dates from the Guiyijun period. ${ }^{219}$ In all, this group of manuscripts is closely linked with Guiyijun society after the end of Tibet's political control.

\section{(ii) Place}

If the colophon mentions the place, it is typically Shazhou 沙洲 or Dunhuang. As monasteries and temples in different regions often had the same name, adding the name of the region in the colophon made the geographical location more specific. The prevalence of these two toponyms in the colophons is clearly the result of the manuscripts coming from a local site. When the colophon omits the name of the region, it is safe to assume the manuscript is still a local product. Although similar practices must have existed in other regions, almost all of the relevant manuscripts are from Dunhuang.

\section{(iii) Monastery}

Not all students were studying at monasteries, and even those who were, did not always write down the name of the monastery. The surviving body of colophons preserves the names of eleven monasteries in Dunhuang. These monasteries-in chronological order of their attestation-are as follows: ${ }^{220}$

$\begin{array}{ll}\text { Liantaisi 蓮臺寺 (Lotus Platform Monastery) } & 867-936 \\ \text { Jingtusi 淨土寺 (Pure Land Monastery) } & 870-979 \\ \text { Lingtusi 靈圖寺 (Spiritual Image Monastery) } & 896-940 \\ \text { Jinguangmingsi 金光明寺 (Golden Light Monastery) } & 905-922 \\ \text { Qianmingsi 乾明寺 (Heavenly Brightness Monastery) } & 915-975 \\ \text { Longxingsi 龍興寺 (Dragon Rising Monastery) } & 917-920 \\ \text { Yong’ansi 永安寺 (Eternal Peace Monastery) } & 923-983 \\ \text { Sanjiesi 三界寺 (Three Realms Monastery) } & 925-975 \\ \text { Dayunsi 大雲寺 (Great Cloud Monastery) } & 958-962 \\ \text { Xiandesi 顯德寺 (Manifested Virtue Monastery) } & \text { ca. } 977\end{array}$

Chengnansi 城南寺 (South of City Monastery)

218 Li Zhengyu 1987, 34.

219 Zhang Xiuqing 2008, 14.

220 Chai Jianhong 2008, 148. The dates to the right indicate the range of dated colophons, when available, linked with each monastery. 
Although the Dunhuang region had seventeen or eighteen monasteries at the time, ${ }^{221}$ not all of them feature in the colophons. This, of course, may simply be the result of where the surviving manuscripts originated from and does not necessarily mean that other monasteries were not involved in similar educational activities. That students identified themselves as belonging to particular monasteries is evidence that they produced the manuscripts while they were studying there. The role of monasteries in this educational arrangement will be discussed below. Monasteries, however, were not the only locations for studying. The manuscripts prove that prefecture and county level schools (zhouxue 州 學 and xianxue 縣學), as well as medical schools existed, although only a few such colophons survive. ${ }^{222}$ The texts copied at these schools were often identical to those studied at monasteries but differed in their context and time frame.

\section{(iv) Student}

The word 'student' is written in a variety of different ways (e.g. xuelang, xueshilang, xuesheng or xueshi). In some cases, we can see that some of the terms may have been abbreviations (e.g. xuelang for xueshilang), while elsewhere the variants signified actual differences. The terms may also have a chronological dimension, as there is evidence that some were limited to certain periods. For example, the term xueshilang was only in use from the end of the ninth century and not during the early decades of the Guiyijun period. ${ }^{223}$ It is significant that those copying the texts identified themselves as students, as the word references a specific context for the production of those manuscripts. This establishes that the texts were copied as part of a curriculum, rather than for devotional or other purposes. The understanding that they were part of a formal educational setting has been essential for reconstructing the school system in Dunhuang and in pre-modern China in general. ${ }^{24}$

\section{(v) Name}

Names are among the most important pieces of information in colophons, for they identify the persons responsible for the creation of the manuscript. With but few exceptions, the students' names are secular. This indicates the students

221 Rong 2013, 119.t

222 Zürcher 1989, 319.

223 Li Zhengyu 1987, 27.

224 See, for the example, Gao Mingshi 1986, Itō 2008. 
were usually neither monks nor novices and they did not intend to join the samgha. The predominantly secular selection of texts they copied confirms this orientation. The surnames appearing in the colophons include Chinese (e.g. Zhang 張, Wang 王, Liang 梁) and Sogdian (e.g. An 安, Kang 康, Shi 史, Cao 曹) ones. In some cases, the name allows us to connect the manuscript to other manuscripts or inscriptions, which can be useful for ascertaining the general period the individual was active in and even learn about his circumstances.

\section{(vi) Action}

The colophon usually ends with a verb specifying the type of action the person in question performed. Most common are the verbs xie 寫 ('to copy') and $j i$ 記 ('to record, note'). Sometimes they follow each other, signifying that the colophon records the act of copying. Usually, $j i$ 記 refers to inscribing the colophon, whereas xie 寫 to writing the main text. When more than one colophon is featured, there may be additional verbs, such as $d u$ 讀 ('to read aloud') or song 誦 ('to recite'). Sometimes the colophon concludes with a particle such as er 耳 ('and that is it').

The above paragraphs exemplify the general structure of student colophons, although in practice individual examples may vary. The students may omit some elements, depending on what they considered important. The most stable items of information are the date, the student's name and the type of action the student performed. Obviously, they may not have always felt it necessary to record they were studying in Dunhuang, as from their perspective this would have been blindingly obvious. In any case, signing one's name as part of a colophon was unquestionably an active expression of ownership, taking both responsibility and credit for having completed the work.

The students' age is of interest, even if the colophons from Dunhuang do not mention it. Researchers often assume they are children but it is not necessarily so. In the colophon of the Astana Lunyu with Zheng Xuan's commentary, $\mathrm{Bu}$ Tianshou wrote in the colophon that he was twelve sui of age. This fits well with the school setting, even if his tender age prompted a number of admiring comments on his literary talent and ability to copy such a long and complex text. Unfortunately, none of the student manuscripts from Dunhuang specifies the age of students. Erik Zürcher attributed manuscripts with rudimentary exercises to small children, offering a vivid description of their work: 'Combined with the known age of many beginners-five or six years-they move readers by the picture they evoke: tip of the tongue protruding; a tiny hand clutching an 
unwieldy writing brush. ${ }^{225} \mathrm{He}$ may, of course, be correct about some manuscripts but it is also likely that some students were older.

Manuscript P.3620, bearing the colophon of Zhang Yichao, the first military commissioner of the Guiyijun state, offers a telling example of how one may be led astray when assuming students to be children. The colophon appears after an 'Untitled song' 無名歌 and states that the text was 'copied by the student Zhang Yichao on the twenty-fifth day of the third month of the wei year' 未年三 月廿五日學生張議潮寫. The year is given in terms of the twelve-year cycle, corresponding to the Year of the Goat. Scholars have commonly equated this with the year 815, primarily because at this time Zhang Yichao would have been sixteen or seventeen years old and thus of suitable student age. ${ }^{226}$ Twelve years earlier he would have been too young and twelve years later, no longer a child. ${ }^{227}$ Yet, Zhang Xiuqing argues that the wei year here might refer to 851 when Zhang Yichao was already fifty-two or fifty-three years old. ${ }^{228}$ She explains that, on the one hand, the copying of such types of secular texts was not in vogue until after the end of the Tibetan period (i.e. 848). On the other, contrary to earlier assumptions, the custom of recording dates using the twelve-year cycle was not limited to the Tibetan period and continued well into the Guiyijun period. Accordingly, the word xuesheng ('student') signified his status in a given context and had nothing to do with his age. Whether or not this was indeed the case with Zhang Yichao, we should not automatically assume that all students associated with monasteries were children.229

Occasionally a student identifies himself as a child, as seen in the colophon of manuscript BD06258, in which 'the student boy Tang Wenying, 學生童子唐文 英 dedicates the merits from copying the Guanyin sutra to his ailing younger

225 Zürcher 1989, 36. One detail to be corrected in Zürcher's description is that students of the period in question would have been holding a pen, and not a brush.

226 Soymié et al. 1991, 110; Li Zhengyu 1986a, 41; Li Zhengyu 1987, 38; Zhang Yanqing 2005, 89. Ikeda 1990, 402 suggests that the manuscript dates to the early ninth century. Mair 1981, 32 dates the wei year to 923, evidently not connecting this Zhang Yichao with the military commissioner.

227 Zhang Yichao's date of birth is unknown, but Zhang Huaishen's stele 張淮深碑, which survives in manuscript copies, states that he was 74 sui when he died in 872 . This allows us to calculate the year he was born. For the text of the stele, see Fujieda 1964.

228 Zhang Xiuqing 2008, 14.

229 We find a comparable example in the Tang zhiyan 唐摭言 (juan 10,112), a collection of anecdotes by Wang Dingbao 王定保 (870-940), which describes how a certain Duan Wei 段維, still illiterate at the age of forty, was suddenly overcome with a desire to study. He went to a monastery where he first learned poems and then was given the Xiaojing, all of which he mastered very quickly. 
sister. ${ }^{230}$ The student presumably stated that he was a boy to distinguish himself from those who were not. Typically the colophons do not provide enough information to determine the student's age but we should not automatically conclude they were children. Nor should we assume that the purpose of studying at a monastery limited to acquiring basic literacy skills, for there may well have been other motivations of which we are not aware.

Last but not least, the colophons contain very little information on students' gender, other than the term xuelang, in which the component lang 郎 on the whole implies a male individual. Only in very few cases is gender mentioned, as in BD06258 above, in which the student refers to himself as a 'boy' 童子. Elsewhere the students are known historical figures (e.g. Zhang Yichao) whose gender is known. At other times the term langjun 郎君 is used, referring to a male of high status. Perhaps the most common type of available information is the student's name, which may be gender specific. While this may often be so, many names do not reveal the gender. None of the cases suggest that the student may have been female.

Another intriguing question is the students' social status. Examples exist of colophons written by members of both ruling families of the Guiyijun period, indicating that at least some of the students were members of the highest echelons of Dunhuang society. Some names appear in other manuscripts, in ledgers and inventories, indicating individuals bearing administrative and organisational responsibilities, which also places them in a higher social strata. The manuscripts show that students studying in monasteries were male members of elite or prominent clans.

\subsection{The main text}

The colophons provide a record of the circumstances related to copying the main text, which was the primary occasion for the creation of the manuscripts. Although the verso of a manuscript often contains a variety of other texts or textual fragments, the colophon normally pertains to the main text on the recto, which must have been the first text written on the scroll. Colophons, or parts of them, may also appear on the verso, yet these instances seem to be copies imitating the one on the recto and thus only indirectly relate to that side of the scroll. The main texts in such manuscripts permit a number of observations.

230 Li Zhengyu 1986a, 41, Zhang Xiuqing 2008, 14. This was, of course, a different type of manuscript and a different type of colophon from those executed in an educational setting. 
One such observation is that the main text is often written in a more formal script than the colophon, which in practical terms means better handwriting. ${ }^{231}$ It is true that the main text itself is, at times, written in an unskilled hand but the hand in the colophon and other miscellaneous notes (e.g. poems, jottings, fragmentary copies of the main colophon, additional colophons) is usually even less skilled. In some cases, the contrast is striking. We may assume the main text to be part of an assignment in which the quality of handwriting mattered, whereas the colophon was an auxiliary notation and not part of the assessed work. The colophon may more accurately reflect how the student normally wrote when not striving to impress. Probably for similar reasons, the miscellaneous notes on the verso of many such scrolls are also typically of lower quality than the main text on the recto. This distinction holds true even if the verso is in several hands.

Another fascinating phenomenon is the limited choice of texts, especially in comparison with the wide range of literature that survives in the Dunhuang corpus. The texts in manuscripts copied by students were relatively short and included specimens from the Classics, vernacular literature, poetry and a variety of primers. ${ }^{232}$ Among the most frequent are the Lunyu (either with or without commentary), Xiaojing, Qianziwen, Taigong jiajiao, Kongzi Xiang Tuo xiangwen shu, Kaimeng yaoxun and Du Zhenglun's 杜正倫 (d. 658) Baixing zhang 百行章 (Stanzas on the Hundred Conducts). ${ }^{233}$ Of these, the last five items are primers whose aim was expressly educational. By contrast, the Lunyu and the Xiaojing were not primers per se but the significance of their core message and their manageable length made them a reliable part of the curriculum.

Manuscripts could also feature poems as the main text. Among the most popular were the poems of Wang Fanzhi 王梵志 (d. ca. 670), the Qin fu yin and the Yanzi fu. ${ }^{234}$ Wang Fanzhi's poems were especially popular and were common even in manuscripts without student colophons. While few of his Buddhist poems survive in transmitted collections, they certainly enjoyed great popularity in Dunhuang.

231 On the differences between formal vs. quotidian hands in early Chinese manuscripts, see Boltz 2012/2013.

232 For an overview of the texts, see Zürcher 1989, 328, Drège 1991, 85-86, Drège 2003 and Itō 2008, 44-58.

233 For the Dunhuang Baixing zhang, see Fukui 1958, Deng Wenkuan 1985, Hu Pingsheng 1990, Zheng and Zhu 2002, 320-348 and Wu Shaowei 2018. For an up-to-date transcription, as well as a translation into Japanese, see Itō 2008, 231-279.

234 On Wang Fanzhi's poems, see Chen 1966, Demiéville 1982 and Kehren 1998/1999. A Chinese language edition is available in Wang and Xiang 2010. 
Students copied other texts but those mentioned above were the most common. The choice of primers is obvious, as their raison d'être was to facilitate learning. Many referenced a larger pool of cultural knowledge in a convenient and accessible manner. Since the four-character segments of primers such as the Qianziwen functioned as mnemonic index cues, by memorising them, students gained access to a much larger body of historical and cultural knowledge. ${ }^{235}$ Other texts contained didactic content and transmitted core social values along with teaching the basic repertoire of characters.

It was undoubtedly important that the primers and other works the students copied consisted primarily of common characters and a relatively narrow range of difficult ones. Similarly, their language was usually simple, with perhaps the sole exception of the Lunyu, in which the overall cultural significance of the work and its emphatic endorsement of learning surely justified its inclusion in the curriculum. The self-contained nature and brevity of separate sections were also features that deemed the text desirable for educational purposes, despite its archaic language and complicated syntax. ${ }^{236}$ These, in turn, would have been resolved by following the teacher's interpretation and not engaging in potential ambiguities.

The length of texts appears to have been equally relevant. The Kongzi Xiang Tuo xiangwen shu is approximately 1,500 characters long; the Qin fu yin 1,666; the Xiaojing about 1,800; the Taigong jiajiao 2,200; the Yanzi fu just under 3,900 and the Baixing zhang about 5,700. ${ }^{237}$ Their relative brevity was ideal for copying on small to medium size scrolls. Manuscript P.3698, for example, a scroll with a complete copy of the Xiaojing and its preface, consists of three sheets of paper, a realistic task for a student to copy within a short period of time. For its 16,200 characters, the Lunyu is once again an exception, but students often copied it in smaller sections. Occasionally, a student would copy the entire text including the commentary.

Some manuscripts contain lines with a succession of repeated characters. Clearly, the aim was to practise the writing of individual characters, yet the sequence of characters usually comes from a known text. ${ }^{238}$ Among the most

235 On this point, see Nugent 2018; cf. Galambos 2015b, 271-272.

236 On the love of learning in the Lunyu, and its contrast with the Western notion of the love of wisdom (philosophia), see Perkins 2006. On the language of the text, see Xiao 2005/2006.

237 These numbers are rough estimates based on unpunctuated copies of the texts. In reality, the numbers would vary depending on whether the students copied the preface and chapter titles.

238 In some cases, the model is an administrative text, such as the verso of BD08172, in which the text copied in this character-by-character manner is an association circular; on these, see 
common texts selected for this exercise was the Qianziwen. A striking case is manuscript S.2703, which contains long repetitions of sequential characters from the Qianziwen. The copying is occasionally interrupted mid-line with a note stating the date (e.g. 'nineteenth day'十九日), demonstrating that the student practised three to five different characters every day, copying each of these between 30 and 100 times. In at least one instance, a comment from the teacher appears, noting how the student was 'gradually acquiring some skill, deserves to be rewarded' 漸有少能, 亦合甄賞. ${ }^{239}$ Manuscripts featuring such repetitive exercises do not contain student colophons, and it is almost certain they were written by students at lower stages of learning.

It is obvious that many of the same texts copied by students in Guiyijun Dunhuang were also popular in other regions of East and Central Asia. The primers recovered from Turfan and Khara-khoto, the two sites yielding the largest collections of medieval manuscripts after Dunhuang, overlap to a significant degree with those at Dunhuang. Many similar manuscripts also survive in Japanese collections. The Qianziwen and the Mengqiu 蒙求 (What Beginners Seek), for example, were among the most important kanbun 漢文 primers in premodern Japan, including the period that matches the Guiyijun period. ${ }^{240}$ Similarly, manuscript copies of the Qianziwen with phonetic glosses in the Tibetan (from Dunhuang) and Uighur (from Turfan) scripts survive, demonstrating the wide influence of the primer among China's neighbours. ${ }^{241}$ In addition to extensively copying the Lunyu, Xiaojing and various primers in Chinese characters, some non-Chinese peoples also translated them into their own languages. Translations of a variety of such texts survive among the rich collection of Tangut material found at the ruins of Khara-khoto. ${ }^{242}$

Finally, a pattern that emerges from this small corpus indicates that students were usually involved in the production of only one manuscript. A rare

Chapter Four of this book. In manuscript S.1619, the student practised eight consecutive characters from Wang Xizhi’s 王羲之 (303-361) Lanting jixu 蘭亭集序 (Preface of Poems Collected from the Orchid Pavilion).

239 On this manuscript, see Li Zhengyu 1986b. Further examples are cited in Zürcher 1989, 315-319.

240 On the Japanese reception of Chinese primers, and especially the Qianziwen, see Chapters 1-2 in Guest 2013. For a comparison of a Dunhuang copy of the Mengqiu with early Japanese copies, see Zhang Nali 2002b; for a collection of Japanese manuscripts of the Mengqiu, see Hayakawa 1973.

241 On the Tibetan manuscript, see Haneda 1923; on the Uighur ones, Umemura and Zieme 2015; Shōgaito and Yakup 2004. On fragments of Chinese primers from Turfan, see Chō 2006.

242 On primers and related texts in Tangut, see Galambos 2015c, 135-176. 
example of the same students signing their names at the end of two manuscripts is scrolls P.2825 and S.705 (mentioned above), recited and copied by Song Wenxian and An Wende approximately a year apart (i.e. 850 and 851). Names may repeat in other documents such as contracts, association circulars or even mural inscriptions but almost never in a manuscript bearing a student colophon. The significance of this phenomenon is that the manuscripts bearing such colophons probably do not represent daily exercises, otherwise we would expect, even in a more or less random sample base, there to be some overlap between manuscripts and students. Instead, surviving colophons record different students writing the same few texts, revealing that copying the main text must have been a significant assignment, perhaps an examination taken the end of an extended period of study. In this respect, the main text would have served an entirely different purpose from the scribble-like notes on the verso, which will be addressed further on in this chapter.

A related phenomenon is that over a hundred-fifty student colophons survive in Dunhuang, whereas they are a rarity in manuscripts from other sites. Aside from Bu Tianshou's copy of the Lunyu from Astana, there appear to be no other examples with colophons resembling the format of those from Dunhuang. On the one hand, this may stem from the motives behind the accumulation of the contents of the library cave and the reasons for its eventual sealing. On the other, the colophon in the Astana Lunyu, discovered at a considerable distance from the manuscripts of Guiyijun Dunhuang both in time and space, evidences the pervasiveness of this format throughout Chinese manuscript culture. The same format must have been shared wherever Chinese characters were in use, even if Dunhuang is the only site where these have survived in any number.

\subsection{The poems}

A number of student manuscripts contain short poems known in modern scholarship as 'student poems' (xuelang shi 學郎詩). ${ }^{243}$ All of these survive as part of the miscellaneous content on the margins and the verso. These poems never constitute the main text, even though the main text itself may be a longer poem (e.g. Qin fu yin, Yanzi fu). This raises the question of which pieces qualify to be called a 'student poem'. In a sense, it is a practical label for a variety of verses students wrote in their manuscripts. Yet they do have shared characteristics such as struc-

243 Marginalia expressing similar sentiments were also present in medieval European manuscripts; see, for example, Avrin 1991, 223-224 and Gehl 1993, 48-51. 
ture, usually consisting of four lines, each with four, five, six or seven syllables. In most cases, they did not survive in transmitted sources, unlike the work of Tang poets such as Li Bai 李白 (701-762) or Gao Shi 高適 (ca. 700-765). Some contain colloquial words and phrases and we may even catch glimpses of humour. In terms of their visual appearance, the poems look haphazard and are often, although not always, written in a careless hand. In this respect, they resemble copies of association circulars and contracts randomly scattered on the verso of manuscripts, without ever becoming the main text on the recto.

Initially, modern scholars assumed that the poems were authored by the students themselves, who composed them either out of boredom or just for fun. Researchers considered them to be directly relevant to the process of copying or to the daily life of students. $\mathrm{Hu}$ Shih saw them as an expression of the difficulties the copyists were experiencing while copying the manuscripts. ${ }^{244}$ Guo Moruo made a similar assertion regarding the Astana Lunyu manuscript copied by Bu Tianshou. Examining a student's poem at the end of the scroll, he confidently asserted that it 'had undoubtedly been composed by Bu Tianshou himself'. ${ }^{245}$

Such a view is, of course, not entirely unreasonable as many of the poems relate to the lore of students copying texts. For example, manuscript S.692 with a copy of the Qin fu yin and An Yousheng's colophon, dated to 919 (see above), includes a poem written in the same hand as the main text and the colophon. The poem itself reads as follows:

rhymes: $\mathrm{x}-\mathrm{a}-\mathrm{x}-\mathrm{a}$

$\begin{array}{ll}\text { 今日寫書了 } & \text { Today I have finished copying } \\ \text { 合有五斗米 } & \text { For as much as five pecks of rice } \\ \text { 高代不可得246 } & \text { If a high fee is unobtainable } \\ \text { 環(還)是自身灾 }{ }^{247} & \text { This is still my own misfortune }\end{array}$

The opening line confirms that the poem has direct relevance to the life of someone engaged in copying texts. The five pecks of rice is a literary trope for

244 Hu Shi 1937, 3-4.

245 Guo Moruo 1972a, 6.

246 代 may be a loan for 貸 ('loan').

247 The character 環, read here as 還, has the signifier 土, rather than 王, and thus may stand for a different word. The word 災 ('disaster, misfortune') is written with the vernacular form 灾, which matches the modern simplified form.

248 Cf. translations in Mair 1981, 45 and Nugent 2010, 48. 
meagre payment. ${ }^{249}$ The rest of the poem discusses the experience of being paid too little for copying, which seems to imply the person in question copied texts for a living. Yet students copied such manuscripts as part of their studies and not in exchange for payment. For this reason, this specific poem is probably not about a student but rather someone who copied texts for a living, perhaps a professional scribe. It must have been the theme of copying texts that resonated with the student who would have appropriated the poem from a different context. It is even more likely he would not have been the first student to adopt these lines for such a manuscript but was simply following previous examples.

This is the only instance of the poem in Dunhuang, although a variation of the first line ('Today the copying is finished' 寫書今日了) occurs at the beginning of another poem in manuscript BD01199 and, in yet another different poem, in $\mathrm{Bu}$ Tianshou's scroll from Astana. ${ }^{250}$ Also, the title of Xin Qiji's 辛棄疾 (1140-1207) lyric 'To the tune of Busuan zi: When I drink, I do not write' 卜算子 ·飲酒不寫書 seems to allude to the same line, although the rest of the poem is different. ${ }^{251}$

Another example is manuscript P.2621 with a partial copy of a leishu 類書 ('encyclopaedia') called Shisen 事森 (Forest of Affairs). The colophon is written by a student called Yuanyi 員義 and dates to the wuzi 戊子 year, which could refer to 868 or 928 . Immediately after the colophon, the same hand as that in the colophon added the following poem: ${ }^{252}$

rhymes: $\mathrm{x}-\mathrm{a}-\mathrm{x}-\mathrm{a}$

$\begin{array}{ll}\text { 寫書不飲酒 } & \text { Copying and [not allowed to] drink wine } \\ \text { 恆日筆頭乾 } & \begin{array}{l}\text { With the tip of my pen normally being dry (i.e. not composing } \\ \text { literature) }\end{array} \\ \text { 且作隨疑過 } & \text { I am about to create arbitrary mistakes } \\ \text { 即與後人看 } & \text { And leave them to my successors to take care of }\end{array}$

The poem seems to express a humorous sentiment that the author copies texts all day without being able to drink wine, yet to compose a real literary work he

249 A commonly cited example for this meaning is a line by Tao Yuanming 陶淵明 (365-427) who is reported to have said about meeting an inspector that he 'would not bow for the sake of five pecks of rice' 為五斗米折腰; see Tian 2011, 76.

250 For the poem in BD01199, see Xu Jun 2000, 918, for that in the Astana scroll, see Guo Moruo 1972a, 6.

251 Wang Zheng 2004, v. 3, 1195.

252 Cf. Mair 1981, 16. 
needs to drink, which is why he will not trouble himself too much with the quality of copying. ${ }^{253}$ Although the poem is about copying texts, it probably related to the life of people who copied texts as a job, rather than students in monastery schools. The fact that the student penning the poem is not its author is confirmed by variant versions in other scrolls. The poem survives in four different manuscripts. A copy in manuscript BD08668 is identical in wording to that in P.2621, showing no variation whatsoever. Manuscript P.3305, a copy of the Lunyu with He Yan's 何晏 (ca. 190-249) commentary, ${ }^{254}$ contains several poems, including a version of this one. The verso of this scroll has a stand-alone colophon from the ninth year of the Xiantong 咸通 reign (868), which was a wuzi year. ${ }^{255}$ Finally, another version appears in manuscript P.2937, a scroll with the Taigong jiajiao dated to the fourth year of the Zhonghe 中和 reign (884)..$^{256}$

In terms of variation, the manuscripts exhibit the following discrepancies against P.2621 translated above:

\begin{tabular}{|c|c|c|c|c|}
\hline P.2621 & 寫書不飲酒 & 恆日筆頭乾 & 且作隨疑過 & 即與後人看 \\
\hline P.3305 & & & 徳 宜 & 有錯 \\
\hline P.2937 & & 必 & 但 須 & 有作 \\
\hline
\end{tabular}

Most of the variation involves cases of phonetic or graphic substitution and thus is unrelated to the meaning expressed in the poem: 干 is a commonly attested variant of 乾; 宜 (LMC ni) is a substitution for the homophonous 疑 (LMC ni); 必 (LMC pjit) is another phonetic substitution for 筆 (LMC pit); ${ }^{257}$ 但 is probably a graphic mistake for 且. More difficult to explain is why 須 (LMC syǎni) is written in place of 隨 (LMC sfiyj) or 徳 (LMC təžk) in place of 作 (LMC tsak), and it is

253 Naturally, this suggests a completely different context from the ritualised transcription of Buddhist scriptures, which required not only sobriety but a series of ritual purifications aiming to remove defilement from the scribe's body. For the phenomenon in Japan, see Lowe 2012 and 2017, 36-45.

254 I.e. Lunyu jijie 論語集解. The end title in the manuscript, however, calls the text simply Lunyu.

255 Of the character 咸 only the right-hand component 戈 is visible but as the character 通 follows it, the only possible reign title can be Xiantong. Furthermore, the ninth year of Xiantong was indeed a wuzi year. The date in the colophon refers to the intercalary eleventh month and while technically it was the twelfth month that was intercalary that year, it is nevertheless a reasonably close match.

256 The date is on the verso and may not be directly applicable to the time of writing the Taigong jiajiao on the recto and the poem, yet it provides a rough temporal framework for the time when the manuscript was in use.

257 On similar homophonic differences in Tibetan prayers, see van Schaik 2007, 195-196. 
likely some of these difficulties are related to the poems being transmitted orally in dialect. Thus 須宜 (LMC syə̌-ni) and 隨疑 (LMC sfiyj-ni) may write the same disyllabic dialectal word not attested otherwise. The only variant relevant to content seems to be 即與 ('and leave them to') vs. 有錯 ('if there are mistakes') in the fourth line, but in fact the meaning of the line remains more or less the same, and thus the variation might simply reflect two different versions as is often the case in this sort of popular verse. Scholars often attribute orthographic instability to the low literacy skills of students, in the assumption they were still at the early stages of their learning career. ${ }^{258}$ It is evident, however, that the poems circulated orally, which leads to variability when written down.

The discrepancies attest to the variability of such poems, although there are also striking similarities between some versions. For example, in P.3305 a different hand in fainter ink copied most of the poem once again, replicating it word for word, along with the variant $d e$ 徳. ${ }^{259}$ Obviously, this was a copy made from the other on the same manuscript and not an alternate version recorded anew from memory or after hearing. More unexpected is that the versions in P.2621 and BD08668 match perfectly, while being different to all other versions. This suggests that the wuzi year in P.2621 may refer to not 868 but 928, which is close in time to the date of BD08668 (i.e. 920). The lesson learnt from these variants is that different students could copy the same poem years and even decades apart. They may have known them in slightly different versions or modified them to fit their own circumstances, but we may be certain they were not the authors. Instead, versions of the poem must have been in common circulation at the time. In fact, the discrepancies between alternate versions may simply be due to predominantly oral circulation.

Another poem that relates to copying or writing is found at the end of scroll P.3192, which contains a copy of the Lunyu with He Yan's commentary. The colophon dates to a bingzi 丙子 year, and a date on the verso helps to identify this as the year 856 . The poem is written in the same hand as the colophon, and possibly the main text. It reads as follows:

258 Mair 2000, 425-426 writes that the students who wrote the poems 'obviously did not possess full literacy' and, in the case of this particular poem, was 'apparently exacerbated by drunkenness'.

259 This is true until the end of this copy, at which point the student ran out of space and wrote 有錯人 instead of 有錯後人看. 
rhymes: $\mathrm{x}-\mathrm{a}-\mathrm{x}-\mathrm{a}$

書後有殘紙

不可列 (裂) 將歸

雖然無手筆

且作五言詩
After my writing, some paper remains

Which must not be torn off to take back home

Thus even though I have no calligraphic skills

I am about to compose pentasyllabic poems

The poem is indeed a pentasyllabic quatrain jotted down on the remaining part of the scroll, which is only a few centimetres wide. Thus, on the surface, it seems the poem references this specific situation. Yet there is another copy of the poem in manuscript P.2947, bearing a colophon dating to a jiayin 甲寅 year (894). ${ }^{260}$ This copy is identical to the previous one, only written in a much less skilled hand. It is similarly located at the end of the scroll, in the middle of a larger stretch of leftover space, as if trying to fill it out as much as possible. In this respect the content of the text fits its physical appearance (perhaps even better than in P.3192). Nonetheless, there is a large time gap between the two copies, with one dating from 856 and the other from a jiayin year (i.e. 894), indicating a thirty-eight year time difference.

Another version of the same poem survives in manuscript P.3322, towards the end of the recto, as the second of three poems. The colophon attributes the copying of the main text, which is an incomplete astrological work, to the student Zhang Daqing 張大慶. Judging from the handwriting, he was probably the individual who wrote everything on this side of the scroll, including the three poems. This version has some minor differences with the other two versions, yet none of these alter the meaning of the lines. Writing 淺 ('shallow'; LMC tshian') in place of 殘 ('remainder'; LMC tshan) is both a graphic and phonetic variation, as is the use of bie 別 ('separately'; LMC piat) in place of lie 列 (<裂 'to tear'; LMC liat). Using shou 首 ('head'; LMC siw') in place of shou 手 ('hand'; LMC siw') in the third line is a phonetic substitution common in other poems as well. The relatively practised handwriting supports the assumption that the substitution may have not been accidental. The colophon dates to a gengchen 庚辰 year, which could be 860,920 or $980 .{ }^{261}$ It is highly unlikely that either version was an

260 Itō 2008, 87 follows Ikeda 1990, 341 in dating the colophon to 834 but the argument dating it from 894 in Zhang Xiuqing 2008, 15 is convincing.

261 Interestingly, the colophon initially began with the jimao 己卯 year, but Zhang Daqing crossed it out and changed it to gengchen, the following year. As the date is the seventeenth day of the first month, only a couple of weeks into the new year, it is likely that Zhang wrote the old year out of habit but corrected it immediately after realising his mistake. 
autograph copy. Rather, they were part of a common lore associated with local manuscript culture and students used them as space fillers.

$\mathrm{Xu}$ Jun was the first scholar to point out that the students who wrote the poems on the margins and empty spaces of such manuscripts were not necessarily their authors. He argued that in many cases students recorded existing poems, such as children's songs and nursery rhymes. ${ }^{262}$ One of the examples he cited was that of manuscript P.3441, the recto of which had a copy of the Lunyu with He Yan's commentary, followed by a colophon dating to 853. The colophon also stated that the text was copied by a certain Gao Yingjian 高英建 who was the adjudicator of students (xuesheng panguan 學生判官). ${ }^{263}$ The verso of the scroll has a number of smaller bits of texts, including association circulars. Among these notes, upside down in relation to two adjacent circulars, the following poem appears in faded ink:

rhymes: $\mathrm{x}-\mathrm{a}-\mathrm{x}-\mathrm{a}$

白玉雖未寶

黃金我未雖(須)

心在千章 (張)至(紙)

意在萬卷書
Although I have never considered white jade a treasure

I have never needed gold [either]

My mind is set on a thousand sheets of paper

My thoughts are focused on ten thousand scrolls

of writings

The handwriting is crude, and the poem contains cases of phonetic substitutions that would normally qualify as blatant mistakes, such as writing 章至 (LMC tşian tşi') in place of 張紙 (LMC trian tşi'). One may argue that the poem reflects the aspirations of a student focused on his studies, rejecting the treasures of the world to busy himself with books. As Xu Jun pointed out, a variant of the same poem also survives in manuscript P.2622, the recto of which contains a series of model letters. The verso of this scroll has a stand-alone colophon which dates to the thirteenth year of the Dazhong reign (859), only six years later than the date in P.3441 (i.e. 853). The text itself is unmistakably a variant of the same poem, even if it is in a manuscript of a different student. The most forceful evidence against considering the students to be authors is the survival of yet another version of the poem on a ninth-century stoneware ewer from the

262 Xu Jun 1994.

263 Cf. Mair 1981, 30. 
Changsha Kilns 長沙窯 in southern China. ${ }^{264}$ The discrepancies of the latter two versions against that in P.3441 are as follows: ${ }^{265}$

\section{P.3441白玉雖未寶 黃金我未須 心在千張紙 意在万卷書}

P.2622 266 非為意 $\square$ 心存

Changsha kiln 非為 千 不 意念藏

Once again, the three versions show some variation, none of which cause a significant change in meaning. Nonetheless, the variants can improve the reading of the first line, as 'I have never considered white jade a treasure' 白玉非為 寶 works better than the version seen in P.3441. ${ }^{267}$ Interestingly, it is not the two Dunhuang versions that are closest but the copies in P.2622 and on the ewer from the Changsha kiln, which show that the differences are not a function of geographical distance. Indeed, the three versions belong to roughly the same period, yet the inscription on the stoneware ewer comes from southern China, over 2,500 kilometres from Dunhuang. As by the ninth century Dunhuang was not even part of the Tang empire, the poems must have spread to the Northwest some time before Tibetan expansion into the Gansu region in the 780s. The occurrence of the same poem in such geographically distant locations proves that even though the Dunhuang students copied it onto the manuscripts in the ninth century, they were not the ones who composed it. The authorship of the verses remains an open question, even if some of them appear to relate to student life or the experience of copying manuscripts. Additional poems and short phrases on objects from the Changsha Kilns also have parallels with those found on Dunhuang manuscripts, including quotes from primers and poems of

264 On the Changsha kilns, see Lam 1990.

265 The characters in version in P.3441 are presented here in their correct form, substituting phonetic loans with the intended character.

266 I slightly modify the transcription of the version in P.2622 in Xu Jun 1994, 19, which gives the third line as $\square$ 竟千張數. High-quality digital photographs make it clear that the second character is 意 (rather than 竟), and the first character is missing altogether. Although the hand is more practised in P.2622 than in P.3441, numerous idiosyncrasies point to a predominantly oral transmission of such poems, as opposed to the main text on the recto. For example, the character 張 uses the component $彳$ instead of the standard 弓; the character which I transcribe as 鈘 is probably a variant of 紙. Itō 2008, 86 follows Xu's reading.

267 Thus in P.3441, sui wei 雖未 (LMC syj vjyj) is probably a phonetic error for fei wei 非為 (LMC fjyj yj). Writing 雖 (LMC syj) instead of 非 (LMC fjyj) may involve an intermediate character such as 維/唯/惟 (LMC jyj), which shares the phonetic component with 雖. 
Wang Fanzhi. ${ }^{268}$ The material confirms that a shared body of mostly non-elite literature was in circulation in southern China and the Hexi region, and possibly elsewhere. This, of course, raises the question whether 'student poems' is an appropriate term, as many of them were originally not connected to student lore. Nevertheless, it may be argued that in the Dunhuang manuscripts they function as student poems, even if they originated elsewhere.

In general, the poems in student manuscripts share a series of traits that bring them together as a group: they have the same or similar rhyme pattern, are located on the margins or verso of scrolls, and are often written in a scruffy hand. Most importantly, they only appear in manuscripts written by students. While some of them indeed seem to relate to student life, the connection is at times tangential at best. The students did not compose the poems but adopted them from an existing pool of verses that circulated orally.

\subsection{Palaeographic peculiarities}

By examining the physical characteristics of manuscripts with student colophons, we notice that most of them are scrolls, fragments of scrolls or, less commonly, booklets. None of the scrolls are very long so they do not feature a wooden roller. ${ }^{269}$ Typically, the recto of a scroll with a student's work only contains a single text, which is followed by a colophon. The verso may include a variety of smaller notes, but these are subsequent additions and postdate the main text on the recto. The paper is also usually of poorer quality, which is common for manuscripts of the Guivijun period.

From a palaeographic point of view, one of the conspicuous idiosyncrasies of student colophons is writing the character xue 學 ('to study; learning') with the variant 斈, a combination of the components wen 文 ('culture; text') and $z i$ 子 ('child'). ${ }^{270}$ As this character occurs in the words xuelang and xueshilang, it is a common element in the colophons (see Table 4 below). This particular character variant is well attested throughout the medieval period and would have been perfectly legible for literate members of society. Remarkably, it is rare in the main text of student manuscripts but common in the colophons.

268 Liu Jingmin 2002; also, McMullen 2013, 84.

269 Among the exceptions are manuscripts P.2808 and P.3666, both of which have thin wooden rollers.

270 On such semantic compound structures, see Galambos 2011, 401-403. 
Tab. 4: Variant forms of the character 學 in the words xueshilang and xuelang in student colophons.

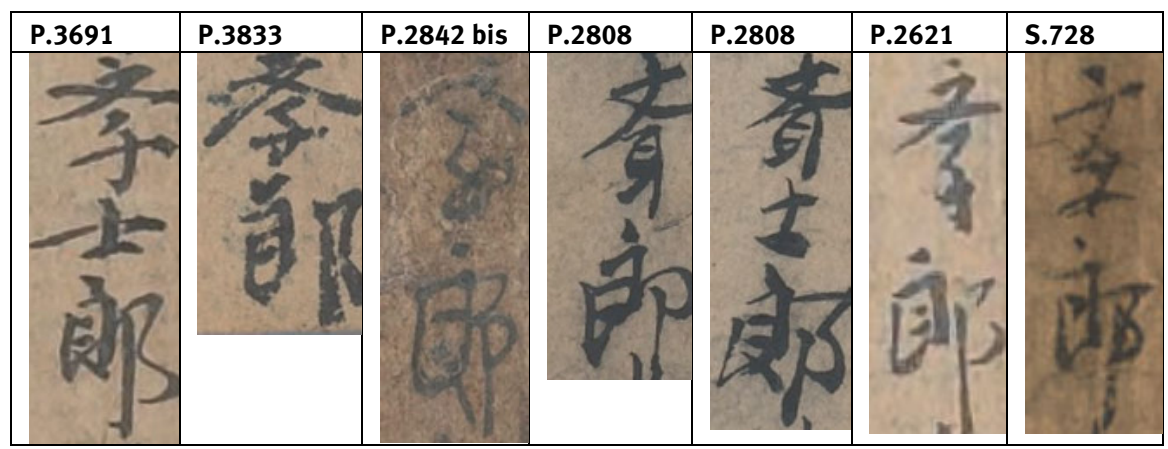

The examples in the table show that the character 學 is commonly written as 斈. In P.2808, however, it is written twice as 齐, a combination of the components wen 文 ('culture; text') and er 耳 ('ear'). Although semantically this combination perhaps makes even more sense for expressing the concept of learning, this form is a well-attested variant of the character $q i$ 齊 ('even, complete'). ${ }^{271}$ It is most likely that these two instances of the character are miswritten. Both lines in which they occur are in the same hand and thus the two forms should probably be regarded as errors specific to this student, rather than a hitherto unrecorded variant of the character 學. The mistake is peculiar as the student clearly tried to emulate the variant 斈 but confused it with an analogous variant (i.e. 章) of a different character (i.e. 齊). This indicates that the student was not entirely familiar with either form and did not use them under ordinary circumstances. His attempt to write the unfamiliar variant was likely due to an awareness of the custom or convention of using such variants in student colophons.

As mentioned earlier, the colophon in manuscripts with student colophons is often written in a scruffy hand, much more so than the main text. As the text copied was probably part of a formal exam-type assessment, the students appear to pay more attention to their handwriting. We see the same phenomenon in other types of manuscripts (e.g. devotional copies of scriptures), in which the colophons are often in a careless hand, but the main text is not. This corresponds to the dis-

271 In fact, this variant of the character 齊 features in a list of such semantic compound characters in manuscript S.388, which is a collection of shorter lexicographic works. Incidentally, the same list also includes the form 斈 as a variant of the character 學. Manuscript S.388 has generated a wealth of interesting research; for some of the recent studies, see Nishihara 2015, Zhu Fengyu 2018 and Ikeda 2018. 
tinction between formal and informal ways of writing, emphasised by scholars working on manuscript traditions. ${ }^{272}$ Of course, there are also cases in which the main text and the colophon are written by different individuals.

As an illustration of the rudimentary level of writing skills manifested in the scribble-like notes in some of the manuscripts written by students, see the examples in Table 5 below. In manuscript P.3369, the word xuelang 學郎 in one of the colophons would be completely illegible without the context. Manuscript P.3305 includes a poem, in which the character 學 in the word xueshenglang 學生郎 is also unusual. Based on the quality of handwriting and the large number of phonetic substitutions in the poem, it is tempting to classify this form as an outright mistake, which would also explain why it does not occur in pre-modern dictionaries. ${ }^{273}$ Yet variants of this form appear in similar manuscripts, such as P.2721 in the same table, suggesting that this may not have been an idiosyncratic error. ${ }^{274}$

Tab. 5: Basic orthographic problems in colophons and scribbles written by students.

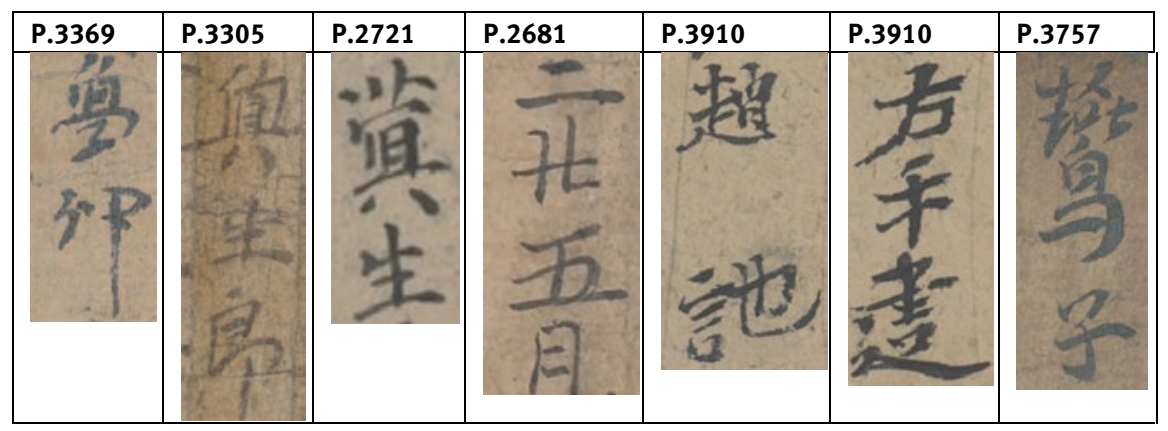

272 E.g. Boltz 2012/2013.

273 To my knowledge, no dictionary, traditional or modern, includes these unusual variants for the character 學, even though they occur in the Dunhuang manuscripts.

274 In fact, the form of the character 學 in P.3369 bears more similarity to this unusual form than the standard character. 
A more obvious mistake appears in an unfinished note at the beginning of manuscript P.2681, in which the Lunyu is the main text. In the note, the date is written as 二廿五日, a blatant mistake since the character 廿 is a ligature standing for the word 'twenty'. ${ }^{275}$ Adding the redundant character 二, the student showed he may not have been completely familiar with how the ligature worked. ${ }^{276}$ The next two examples are from the back cover of codex P.3910, both featuring serious orthographic problems. The first phrase reads 'Zhao recorded' 趙記 but the character 記 is written as 訑, that is, a combination of the components 言 and 也. The Longkan shoujian 龍弇手鑒 records this form as a variant of the character 詑 (tuo, 'to cheat'), whereas the Yupian 玉篇 lists it as a standard character with the same meaning (i.e. 'to cheat') but different pronunciation (i.e. yi). It is apparent that what we see in the manuscript is a mistake made by someone whose writing skills were as yet undeveloped. The quality of handwriting in the booklet seems to corroborate this assumption. The second phrase from the same manuscript reads 'wrote it with his right hand' 右手書之 but the words 'wrote it' 書之 are written as a single character, as if the character 之 was the component 定 at the bottom. Once again, the error indicates an individual of minimal writing skills. Finally, the last example from manuscript P.3757 shows that the first character of the word yanzi 鷰子 ('swallow'), a variant of yan 燕, is written in an almost indecipherable way. In manuscripts P.2681 and P.3910 the characters were probably not written by the person copying the main text but an even less experienced student who made the notes at a later point in time. Nonetheless, the examples provide evidence of the palaeographic peculiarities common in student manuscripts.

\subsection{Scribbles on the verso}

In addition to the literary texts students copied formally, the manuscripts often contain fragments of pragmatic texts related to social and economic matters. Occasionally complete documents exist but, more often than not, only the first lines or words are present. Similar texts also survive among the Dunhuang manuscripts as documents used by the local population in the course of their daily life. Naturally, these are invaluable for the study of the social and economic history of the region. Distinguishing the copies made by students is usually relatively straightforward, but

275 The character nian 廿 is written here as a variant of the form \#, which was common in medieval manuscript culture; see Huang Zheng 2005, 291. Of course, the form H, which is essentially a doubling of the character + ('ten'), is in full accord with the origin of the character.

276 The character $r i$ 日 is written here in a way that resembles the character 月, a phenomenon relatively common in manuscripts from this period. 
in some cases the difference is not immediately apparent. Fragmentary copies of such documents usually appear in manuscripts that contain other texts copied by students, which, by default, signify a connection with educational practices.

The co-occurrence of educational texts and fragments of social and economic documents on the same physical manuscript is a consistent pattern that merits closer examination. One of the aims of such an exercise would be to identify additional manuscripts that originate from educational settings, for this would have obvious implications for the function of those copies. Clearly, students were responsible for the production of many more manuscripts than is normally assumed. We are therefore compelled to re-examine some texts and consider whether they should be treated as actual documents or as copies made by students for the purpose of practice. The latter group is also a reminder that it is sometimes more appropriate to define texts in terms of their function, rather than genre or content.

While the number of manuscripts featuring student colophons is limited, the presence of texts commonly copied by students may link further items to learning practices. ${ }^{277}$ Some of these will inevitably be of a different origin but some will feature visual patterns confirming an affiliation with students. For example, Dunhuang students often copied the Xiaojing, which had an established connection with learning throughout the medieval period. The text is particularly suitable for this purpose as it has a relatively limited repertoire of common characters and, at the same time, propagates the value of filial piety, a fundamental virtue of traditional society. Moreover, its brevity makes it an ideal text for copying.

More than thirty manuscripts of the Xiaojing survive in Dunhuang, including versions with (e.g. P.3274, P.3378, P.3382, P.3816) and without (e.g. P.3369, P.4897, S.3993, S.5821) commentary. ${ }^{278}$ Some are complete, but damaged or fragmentary copies also exist. In addition, there are many other scrolls that contain the title (on the verso), without the text itself being present anywhere on the scroll. While it is certain that not all copies of the Xiaojing can be attributed to students, some of them have colophons to this effect, attesting to the popularity of the text in such a context.

The majority of the surviving Dunhuang copies of the Xiaojing do not have student colophons, which in principle makes their connection to student life uncertain. However, when these manuscripts are compared to those containing colophons, some display similarities indicating a shared background. In some cases, the manuscripts are visually comparable to the ones written by students, featuring similar

277 For a similar effort, see Mair 1981.

278 A collection of facsimile reproductions of the Xiaojing manuscripts from Dunhuang is available in Chen Tiefan 1977. Cf. Hayashi 1976, Chen Tiefan 1978 and Zhu Yuqi 2010. For an overview of relevant Dunhuang manuscripts in a Western language, see Drège 2014c. 
handwriting, size and layout. In other cases, the scribbles and notes on the verso resemble those in manuscripts produced by students. Although often seen as random and inconsequential, the scribbles collectively form a pattern that may contribute to our understanding of how students used such manuscripts.

\subsubsection{Manuscript S.728}

Manuscript S.728 can be examined as a practical example. This is a $180 \mathrm{~cm}$ scroll featuring an almost complete copy of the Xiaojing written in a relatively good hand on a stained, yellowish paper. The scroll currently consists of four full sheets of paper and a largely missing (i.e. torn) fifth one at the very beginning. Since only two lines are missing from the opening portion of the Xiaojing, the first sheet must have contained quite a bit of additional text. The extant sheets comprise 23-24 lines of text, and it is likely that the first sheet would have been of the same size, which means that the lost text was about 19-20 lines long. This amount of paper would comfortably fit the 15-17 lines of the 'Preface', with the same character size and spacing. ${ }^{279}$

Although the end of the scroll is complete, the left edge of the last sheet has a narrow strip of discoloration, revealing that it must have been glued to something else (Fig. 26). As additional sheets of paper would have been glued from the other side, and with a narrower overlap, the darker paper must be a trace of a no longer present wooden roller. In turn, the roller suggests that the scroll was not only an assignment the student submitted as assessed work but also a manuscript that remained in use for a certain amount of time. The roller facilitated the day-to-day handling of the scroll and protected it from damage.

279 An example of such a fragment is P.4628, which contains the beginning of the preface of the Xiaojing but not the text itself. The fragment, however, is in an entirely different hand and so it is not the missing portion of S.728. 


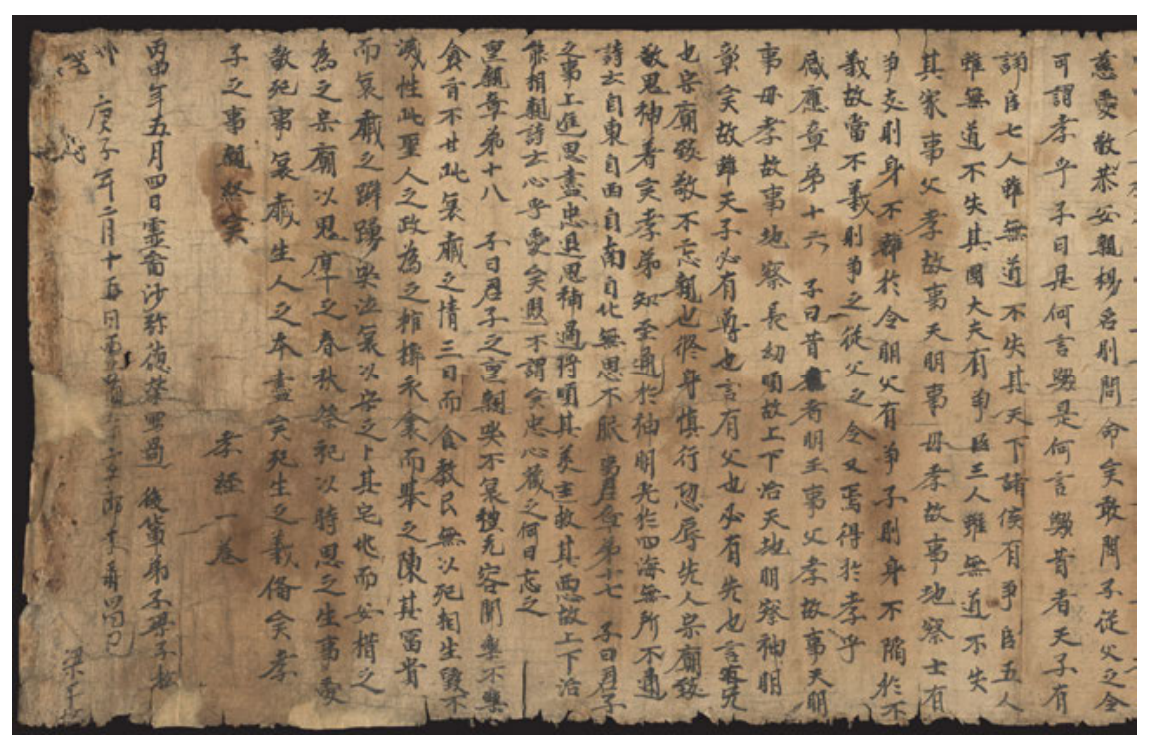

Fig. 26: The end of recto of manuscript S.728 with the two successive colophons. $(30 \times 180 \mathrm{~cm}$; The British Library)

The Xiaojing ends with an end title, which is followed by two consecutive colophons, each on a separate line. The second of these is indented and may or may not be in a different hand. ${ }^{280}$ The two colophons read as follows:

\section{丙申年五月四日靈圖沙彌德榮寫過 後輩弟子梁子松}

Copying completed on the fourth day of the fifth month of the bingshen year (936) by Derong, śrāmanera of the Lingtu [Monastery] Junior disciple Liang Zisong. ${ }^{281}$

庚子年二月十五日靈圖寺斈郎李再昌巳(記) 梁子松

Recorded on the fifteenth day of the second month of the gengzi year (940) by Li Zaichang, student of the Lingtu Monastery. ${ }^{282}$

Liang Zisong

280 Above the indented second colophon, the word xuelang 斈郎 is written sideways, at an angle. It was followed by one more character which is no longer visible. To the left of the beginning of the second colophon are another two-unfortunately illegible-characters in the same hand, similarly, written sideways.

281 Translation based on Mair 1981, 46.

282 Ishihama Juntarō 石濱純太郎 (Hayashi 1976, 37), Mair 1981, 46 and Drège 2014c, 41 read the name as Li Erchang 李爾昌, although Mair indicates his uncertainty regarding the second character by adding a question mark after it. Others (e.g. Ikeda 1990, 477, Itō 2008, 46) correctly read it as Li 
As the second colophon shows, the name Liang Zisong appears once more, on its own, on a separate line, near the bottom of the scroll. ${ }^{283}$ It is uncertain what it signifies in this place but it is the name of the same student named at the end of the first colophon. Another problem concerns the meaning of the character $巳$ at the end of the second colophon. In my translation, I read it as the verb 'to record', normally written with the character 記 or 紀, which would be consistent with the format of colophons in general.

In both colophons, the date appears in the cyclical format and is thus ambiguous. Within the Guiyijun period, when manuscripts with student colophons were in vogue, the bingshen year could refer to 876, 936 or 996, while the gengzi year, to 880,940 or 1000 . Of these, the dates 936 and 940 are the most probable, primarily because Derong is also mentioned in a commemorative inscription from 950 (P.3390), by this time with the title Master of Discipline (shimen falu 釋門法律). ${ }^{284}$ Significantly, the dates in the two colophons are four years apart. Assuming that the first date records the actual time of copying the Xiaojing, we may ponder the significance of the second colophon from four years later. Clearly, it does not refer to the act of copying, it merely states the second colophon itself dates to a particular time. The question is was prompted Li Zaichang to add his colophon to the first one.

Regarding the identity of students, the two colophons mention three persons, each with a different title or rank. Derong, who did the copying, is a novice monk (shami 沙彌, i.e. śrāmanera) of the Lingtu Monastery. This is a rare instance in which the student is not a secular person but a member of the monastic establishment. He omits the word 'monastery' ( $s i$ 寺) but this poses no difficulty for interpreting the colophon. Liang Zisong, whose name appears after the first part of the colophon, is a junior (lit. 'later generation') disciple (houbei

Zaichang 李再昌. In Guiyijun manuscripts, the character 爾 most often appears in its nonstandard form as 尔 (Huang Zheng 2005, 103), whereas the character 再 is commonly written in a way resembling that in the colophon (ibid., 532). In addition, the given name Zaichang occurs, with other surnames or by itself, in many other manuscripts from Dunhuang (e.g. S.2894, S.8426).

283 Itō 2008, 46 follows Ishihama Juntarō (Hayashi 1976, 37) in reading the last character in the name (song 松) as the verb jiao 校 ('to edit, proofread'), no doubt in an attempt to locate the verb and make sense of the note. However, the same name features in the first colophon and, as will be seen below, also appears on the verso of the manuscript, confirming that the last character here is indeed song 松.

284 This inscription survives in manuscript P.3390. Derong was a brother of Zhang Yingrun 張 盈潤 who had also studied in the Lingtu Monastery, as seen from a colophon dated to 827 (P.5011); Chen Zuolong 1978, 75; Li Zhengyu 1987, 35-36. For this reason, Derong (whose secular surname was Zhang) cannot be the same person as Liang Zisong. 
$d i z i$ 後輩弟子) with a non-monastic name. Finally, the person who recorded the second colophon is Li Zaichang, a student of the Lingtu Monastery. The use of the word guo 過 is somewhat unusual, acting as a resultative complement that denotes the completion of an action.

In its current form, the scroll presents a complex arrangement of texts and notes of different periods. The verso contains numerous shorter notes, which at first glance appear to be random scribbles without any particular order or significance. Some of these textual fragments are upside down in relation to others, amplifying the impression of it all being haphazard and disconnected. Some consist of merely a few characters that are difficult to interpret without context. The first string of text at the beginning of the verso reads:

\section{五月五日天中節 一切惡}

On the fifth day of the fifth month, during the Tianzhong Festival, all bad...

Although the line ends mid-sentence, it is long enough to recognise the beginning of an incantation known from transmitted sources and several Dunhuang manuscripts. The complete text appears on the verso of manuscript S.799, a two metre long scroll with a superb copy of the Guwen Shangshu 古文尚書 (Old-Text Version of the Exalted Documents). ${ }^{285}$ The incantation itself expresses a wish that all bad things would be extinguished on the day of the Tianzhong (i.e. Duanwu 端午) Festival. ${ }^{286}$ The full version reads as follows:

\section{五月五日天中節一切惡事盡消滅急急如律令}

On the fifth day of the fifth month, during the Tianzhong Festival, may all bad things completely vanish, at once and immediately, as if according to statutes and ordinances!

A slightly different variant of the same incantation occurs on the verso of manuscripts BD03106. This version reads:

285 This is an incomplete section of the so-called 'Old-Text' version of the Shangshu, which features a preface and commentary ostensibly written by Kong Anguo 孔安國 (d. c. 100). Of the 51 copies of the Shangshu that survived in the Dunhuang library cave, 49 belong to this version and two to Lu Deming's 陸德明 Shangshu shiwen 尚書釋文 (Textual Explanations of the Exalted Documents); Xu Jianping 2018, 158-159. There is also a Tibetan manuscript (Pelliot tibétain 986) with a loose translation of the text; Coblin 1991 refers to it as a 'paraphrase'.

286 Xu Jun 2000, 190. 


\section{五月五日天中節赤口亦 (惡) 舌自消滅急々如令}

On the fifth day of the fifth month, during the Tianzhong Festival, may the red mouths and evil tongues disappear of themselves, at once and immediately, as if according to ordinances!

The 'red mouths and evil tongues' is a reference to the potentially harmful effect of sorcerers, perhaps also indicating talk that is toxic and malicious. ${ }^{287}$ Additional variants are also known from both manuscripts and transmitted texts. ${ }^{288}$ The formula 'at once and immediately, as if according to statutes and ordinances' 急急如 律令 was originally an expression used in official documents during the Han dynasty but later became the closing part of some Daoist incantations. ${ }^{289}$ As the fragment in S.728 includes the first two characters of the second segment, it is certain that it refers to the version preserved in S.799 and not the one in BD03106, in which the second segment is different.

287 Mollier 2007, 91-92. The expression 'evil tongue' 惡舌 is written here with the character $y i$ 亦 ('also'), which is a mistake. Xu Jun 2000, 857 reads the character 亦 in BD03106 as an error for 赤, resulting in the phrase 'red tongue'. Moreover, he transcribes the very end of the incantation as 葱葱 女+含\}, which he interprets as a corruption of the characters 急急如; the manuscript, however, writes the phrase 急々如令 correctly. What Xu reads as the single character \{ 女+含\} is in fact the characters $r u$ 如 and ling 令 written side by side horizontally. The unusual arrangement is simply the result of the writer running out of space and writing the second character to the right of the first one.

288 Zhang Xiaohong 2019, 22. An unfinished fragment also appears on the verso of manuscript P.3812.

289 Miller 2008; cf. Mollier 2007 and 2008; Sakade 2003. 

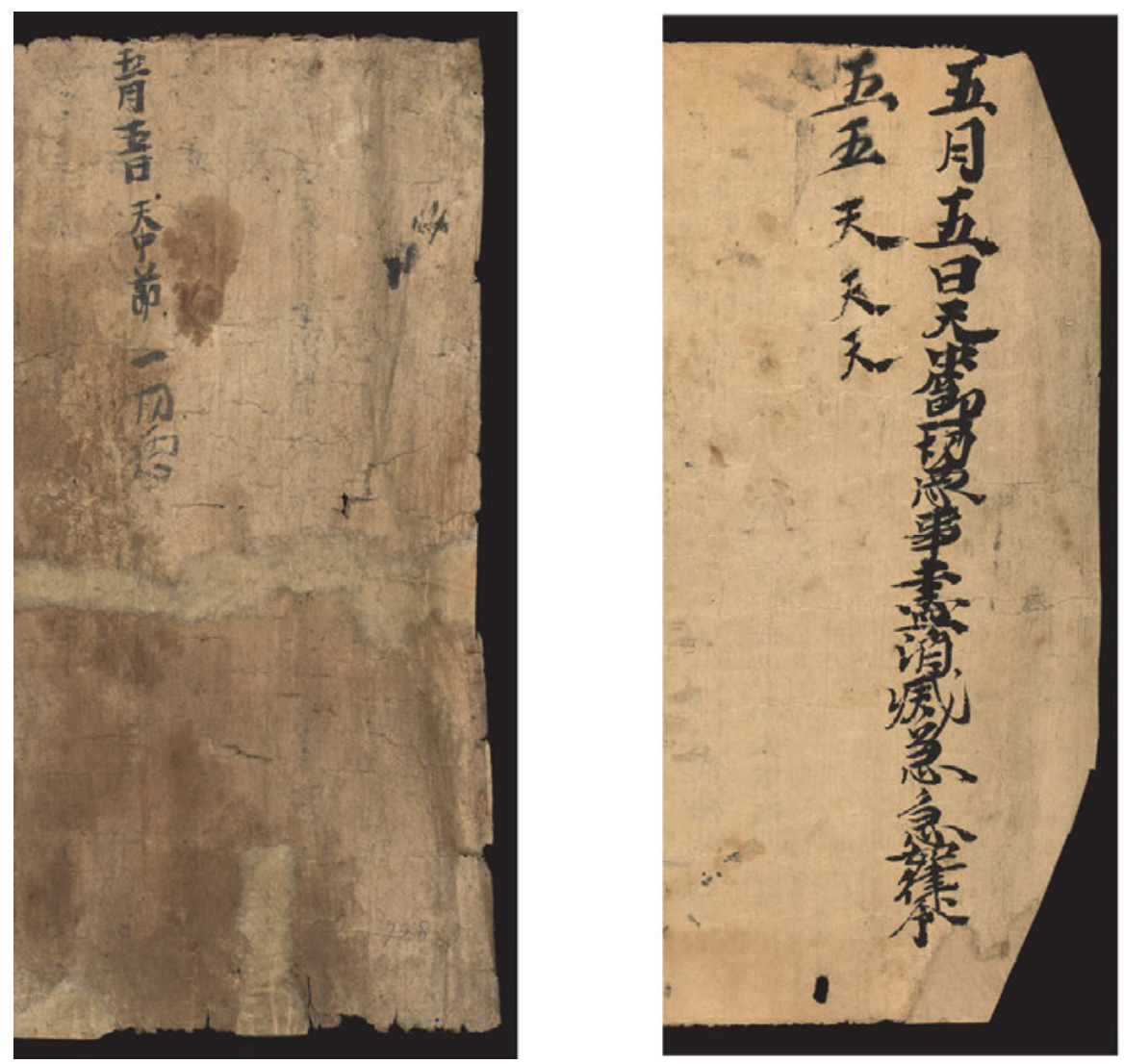

Fig. 27: The incantation of the Tianzhong Festival on the verso of manuscripts S.728 (Xiaojing; left) and S.799 (Guwen Shangshu; right).

Fig. 27 shows this line of text in S.728 (left) and S.799 (right) side by side. The hand in the first manuscript is relatively unskilled, whereas the one in the second is more confident, even though the line itself is not entirely straight. ${ }^{290}$ In S.799, a different hand began copying the characters 五 and 天 but stopped after five characters. This was probably not an aborted writing exercise but a note reminding the student what he was supposed to practise. The unfinished incantation in S.728 may have been a similar notation telling the student what the

290 There are, of course, also some problems with spacing, as it is visibly inconsistent in this line. Yet the characters themselves are relatively well written. 
assignment was. He made a note of what he had to do and then completed the exercise itself on a different sheet of paper. The fact that in both manuscripts the incantation appears at the very beginning of the verso points to a comparable context.

It is significant that the first colophon on the recto of S.728 dates to the fourth day of the fifth month, that is, the eve of the Tianzhong Festival, which fell on the fifth day of the fifth lunar month. Therefore, the student most likely wrote the fragmentary incantation at the beginning of the verso of this scroll either on the night before the festival or on the day of the festival, when the second colophon was still absent. In this way, the final form of the manuscript took shape over the course of several years and students added notes to the scroll in an irregular manner, moving from one side to the other. This does not mean it was done randomly, only that it is difficult now to reconstruct the chronological order in which the scroll arrived at its current form. The incantation of the Tianzhong Festival with a known date is a rare opportunity to document some of the stages in the formation of such manuscripts.

Continuing further along the verso of S.728, the words 'This is Futong incurring another person's anger...' 此者富通得人憎 appear. The characters seem to be in the same, or a similar, hand as the unfinished incantation to the right. The words provide no context but Futong 富通 is without doubt a personal name. In fact, a certain Zhang Futong 張富通 is mentioned in a solitary colophon on the verso of manuscript P.3698, a copy of the Xiaojing examined above. ${ }^{291}$ Significantly, the name occurs in a colophon dated to the gengzi year (940), which matches the year of the second colophon written by Li Zaichang on the recto of S.728. Naturally, the Xiaojing, the context, the given name and the year all point to a connection between the two manuscripts, indicating that the person named Futong here is probably the Zhang Futong mentioned in P.3698.

Returning to S.728, the notes and scribbles on the verso also contain bits of texts relating to the recto. A case in point are a few phrases from the Xiaojing, as well as the names Li Zaichang and Liang Zisong. Indeed, while Liang Zisong is named in the first colophon on the recto as a 'junior disciple' 後輩弟子, on this side he is called 'the student Liang Zisong' 斈郎梁子松. Another fragment of text says fengchi xiuzao dawang 奉敕修造大王, ${ }^{292}$ in which the term dawang 大王

291 A different person called An Futong 安富通 appears on the verso of manuscript S.1478 in a contract copied as a writing exercise.

292 The character 造 is not entirely clear in the manuscript, which is why Hao Chunwen (1993, 77) initially transcribed the line as 奉敕修 $\square$ 大王. My own transcription follows the later reading in Hao and Shi 2003, 579, which seems to match what is visible in the manuscript. 
('great king') most likely referred to Cao Yijin 曹議金 (r. 914-935), the first ruler of Dunhuang from the Cao family. We know that the term dawang was used in Dunhuang in reference to Cao Yijin from 931 and this remained a common way of referring to him until 964 , long after his death in $935 .{ }^{293}$ This time frame fits perfectly with the dates of the colophons on the recto (i.e. 936 and 940), and provides supporting evidence for interpreting the cyclical signs as these particular years.

The verso of the scroll also contains a four-line poem about a student involved in copying texts as a form of exercise. As can be seen on the left side of Fig. 28, the text is arranged in a transparent layout clearly separating each seven-character line as a means of emphasizing the poem's parallel structure. The text reads as follows:

\section{斈郎大歌 (哥)張富千, 一下趁到孝經邊。 \\ 太公家教多不殘, 㥪玀兒實鄉偏。}

The student, big brother Zhang Fuqian,

All of a sudden goes rushing off to his Xiaojing,

His Taigong jiajiao is not incomplete at all,

He is a clever fellow, truly an eccentric..$^{294}$

293 Hao Chunwen 1993, 77, quoting Rong Xinjiang 1990 on the appellations of the military commissioners of Dunhuang during the Guiyijun period.

294 I adopt, with slight modification, the translation from Mair 1981, 46 but follow the transcription in Xu Jun 2000, 855. 


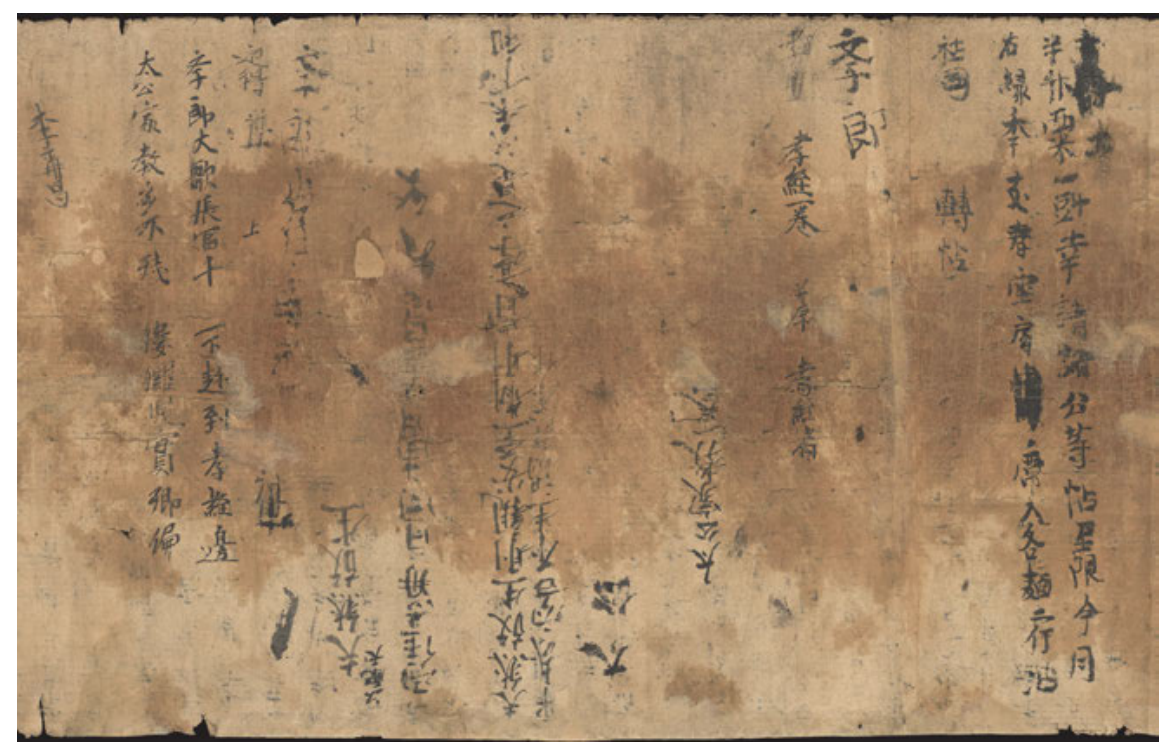

Fig. 28: Detail from the verso of manuscript S.728.

The last line of the poem is difficult to interpret in its current form, not least due a missing syllable. The word louluo 㥪玀, which Mair translates as 'clever fellow', is a term written in the Dunhuang manuscripts with a variety of characters (e.g. 婁羅, 樓玀, 嘍囉, 僂玀), signalling that it may have been mostly outside the realm of written language or that it is a non-Chinese word. Initially, the word seems to have mostly had a positive connotation but in time it also acquired a pejorative meaning. ${ }^{295}$ The name Zhang Fuqian does not occur anywhere else in the manuscript. As seen above, the verso contains a fragmentary reference to a certain Futong, who may have had the surname Zhang, but there is not enough evidence to connect the two names. In fact, as the constituent characters of Fuqian mean 'rich' + 'thousand', the name may have functioned as a 'speaking

295 On the term's meaning and origin, see Xu Shiyi 2005. An interesting case where the word is used to translate a foreign term is found in the Jiu Tang shu 舊唐書, which mentions that the words han julu 含俱録 in the title of Mouyu Qaghan 牟羽可汗 (r. 759-780) meant louluo 婁羅 in Chinese (Jiu Tang shu, 5204). In this, han julu 含俱録 (LMC: xfam kfiyă lywk) is probably a scribal error for he julu 合俱録 (LMC: xhap kfyə̌ lywk), which in turn stands for alp külüg ('brave and famous'); see Hamilton 1988, 97 and Rybatzki 2000, 238. Sam van Schaik notes (personal communication) the existence of a similar Tibetan word, le-lo, meaning a 'lazy person'. 
name' designating students of wealthy families. The Zhang clan was among the most affluent families in the region, even after the Cao dynasty took over. Although this is merely a hypothesis, the poem may well have referred to such students in general or perhaps someone in particular without using his real name. ${ }^{296}$

As the name Li Zaichang appears next to this poem, $\mathrm{Xu}$ Jun suggests he may have been its author. ${ }^{297}$ But the name is in a different hand and at an angle to the vertical lines of the poem and thus probably does not directly relate to the quatrain. Alongside the variety of textual fragments on the verso of the scroll are a series of titles in a seemingly arbitrary randomness. In total, the verso contains the following titles, written in at least two different hands:

\section{Dasheng baifa mingmenlun kaizong yiji 大乘百法明門論開宗義記}

Xiaojing 孝經

Taigong 太公

Taigong jiajiao yi juan 太公家教一卷

shesi zhuantie 社司 轉帖

Xiaojing yi juan bing $x u$ 孝經一卷 並序

shesi zhuantie 社司 轉帖

The titles occur in this order but not one after the other, as there are other bits of texts or stretches of empty space between them. Moreover, as mentioned earlier, some are upside down in relation to others, so they do not appear as a list but are scattered without any discernible order. The Dasheng baifa mingmenlun kaizong yiji was a Buddhist text composed, based on Faxiang 法相 doctrine, by the monk-scholar Tankuang 曇曠 while staying at Dunhuang during the Tibetan period. ${ }^{298}$ This is followed by the title of the Xiaojing, repeated later with the addition of the words yi juan 一卷 ('in one juan') and bing $x u$ 並序 ('plus the preface'). Another title is the Taigong jiajiao, a primer commonly found in similar manuscripts. Though it is not surprising to see this title on a scroll created by students, there is no sign of the text itself. But the title appears twice, once in full form and another time as a two-character abbreviation. As witnessed above,

296 Nonetheless, the given name Fuqian is attested in Dunhuang manuscripts as part of real names, e.g. Ma Fuqian 馬富千 (P.2944), Linghu Fuqian 令狐富千 (P.2953).

297 Xu Jun 2000, 85.

298 On Tankuang and his teachings, see Ueyama 1964, Yamaguchi 1965, Meinert 2007, 248251 and Chō 2016. 
the titles of the Xiaojing and Taigong jiajiao appear together in the student poem on the same side of this manuscript, attesting to their close connection with student life in general, and perhaps with these students in particular.

The third title appearing on the verso of the scroll is not really a title but the words shesi zhuantie 社司 轉帖, which is the heading of circulars issued by the management of local associations. There are two instances of this heading on the verso of our scroll, both written apart from other bits of text. ${ }^{299}$ The one near the centre of the verso is followed by two lines of text from the body of the circular, which allow us to establish that the circular reads in vertical columns from left to right, in contrast to the usual right-to-left sequence of Chinese lines. The other heading near the end of the verso is only followed by a single character from the text of the circular but as it appears to the right of the heading, it is enough to show that, once again, the lines read from left to right. Similar examples of unorthodox ways of writing Chinese characters will be examined in detail in Chapter Three.

\subsubsection{Manuscripts S.707 and P.3698}

The next example is manuscript S.707, another Xiaojing scroll written by a student. The beginning of the scroll is missing but the end is complete. The main text and the colophon appear to be written in the same hand, although the colophon is in slightly smaller characters and fainter ink. It reads as follows (Fig. 29):

\section{同光三年乙酉歲十一月八日三界寺學仕郎郎君曹元深寫記}

Record of copying on the eighth day of the eleventh month of the yiyou year, the third of the Tongguang reign (925), by the langjun Cao Yuanshen, student at the Sanjie Monastery.

299 Traces of the character 社 seem to be present in two more instances but are too faint to allow a confident reading. 

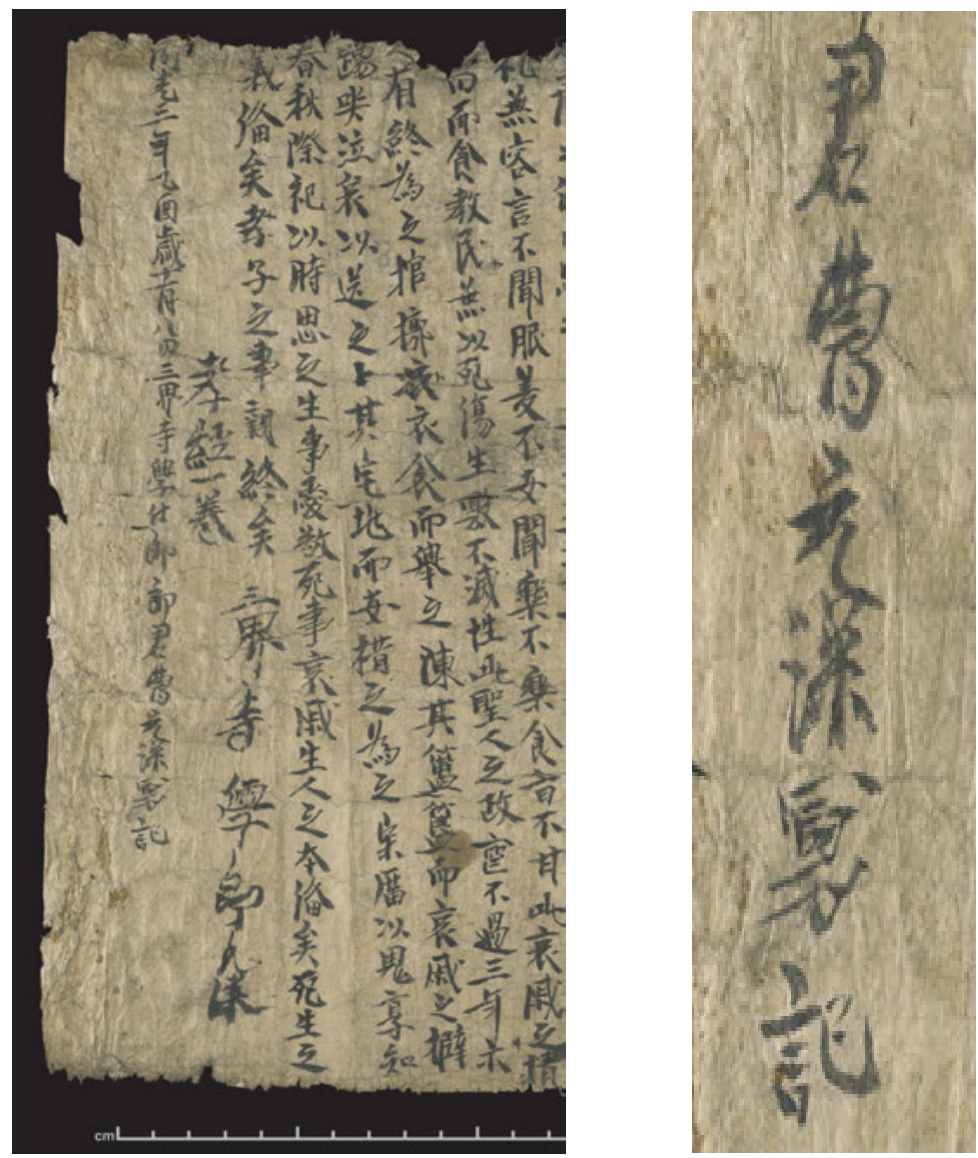

Fig. 29: The end of the Xiaojing and the colophon in manuscript S.707 (left), with the name of Cao Yuanshen enlarged (right). $(29.2 \times 67.5 \mathrm{~cm}$; The British Library)

The first remarkable detail about this colophon is that it was written by Cao Yuanshen 曹元深 (d. 944) who was to become the ruler of Dunhuang, fourteen years later, in 939. The term langjun 郎君 ('young lord, young scholar') seems to signify social rank that elevates Cao Yuanshen above other students who did not use such designations. Cao's case immediately provides some context to the identity and social status of students studying at Buddhist monasteries, signalling that they were from an elite background, belonging to the region's prominent families. The preservation of their scrolls in a monastic library may be due to the monaster- 
ies wishing to maintain a bond with the families. ${ }^{300}$ Providing education to the political elite certainly helped ensure the goodwill of these clans, especially once the students took on leading roles in society. The manuscripts would have functioned as tokens of the bond between the monasteries and political power.

The verso of the scroll contains a number of scribble-like notes similar to those on the verso of S.728, some only a character long, others longer. All are in the same hand, which could be that of Cao Yuanshen. The notes mainly comprise random snippets taken from the colophon on the verso, and multiple instances of the beginning of a poem about a langjun. This poem survives in full in other manuscripts (e.g. S.5711), here only fragments from the beginning are present. The longest segment is the first line: 'the young scholar must establish himself' 郎君須 立身. ${ }^{301}$ At the end of these fragments the note 'scroll written by the langjun Cao Yuanshen' 郎君曹元深書卷 and in the next line the name 'the langjun Yuanshen' 元深郎君 (Fig. 30) appear.

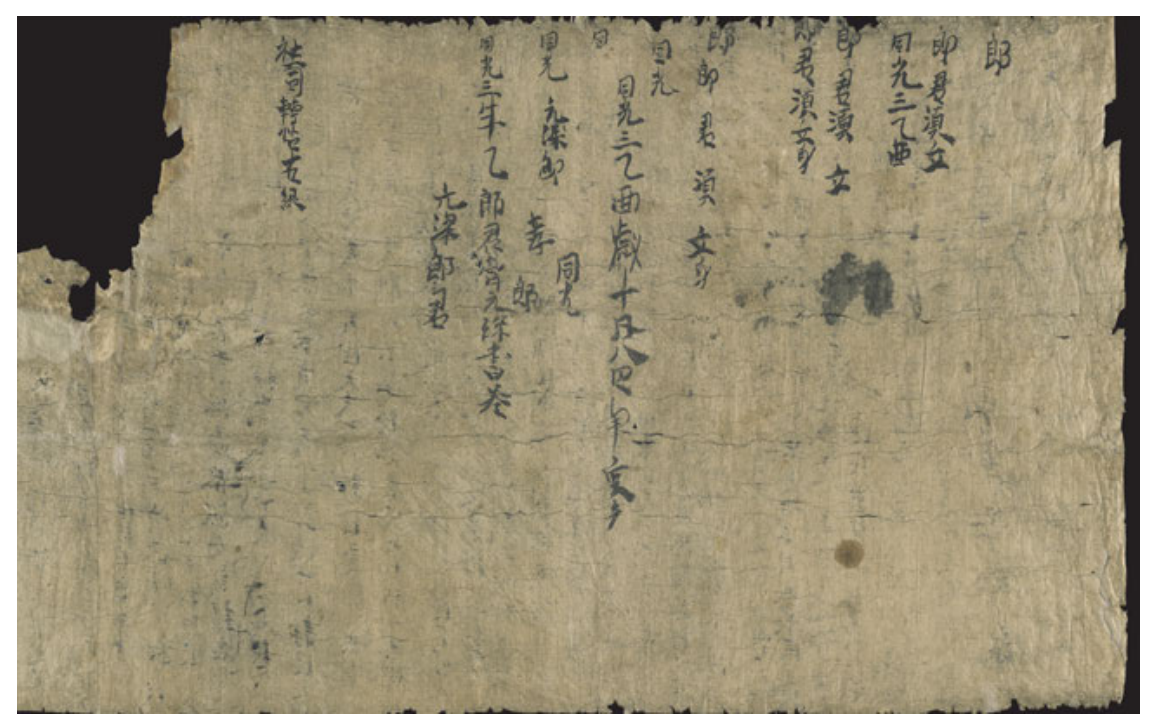

Fig. 30: Section of the verso of manuscript S.707.

300 I am grateful to Stefano Zacchetti for suggesting this reason for the survival of student manuscripts in the Dunhuang library cave.

301 The poem seems refer to the sons of prominent families copying the Xiaojing. Indeed, the poem itself alludes to the following line in that text: 'Filial piety begins with serving one's parents, continues with serving one's ruler and ends with establishing oneself' 夫孝, 始於事 親, 中於事君, 終於立身. 
Amidst these fragments of texts is the character xiao 孝 ('filial piety'), probably an abbreviated reference to the Xiaojing. Finally, the last line of text on the left, standing apart from everything else, is the beginning of an association circular, which breaks off after six characters. Overall, such seemingly random bits of text establish a clear connection with the Xiaojing in Cao Yuanshen's hand on the recto. An obvious similarity with S.728 above is that the verso contains two of the same titles (i.e. Xiaojing and shesi zhuantie).

Yet another example of a Xiaojing manuscript in a student's hand is manuscript P.3698. Due to damage to the colophon, the name of the student is missing, all that can be read is that he copied the text in a jihai 己亥 year, which probably corresponds to $939 .{ }^{302}$ Additional support for this date comes from Zhang Futong's colophon on the verso, dated to the gengzi year. Gengzi is the following year in the sixty-year cycle and, as mentioned above, in this place must have signified the year 940. Another line on the verso, possibly a beginning of a contract, includes the date 'eighteenth day of the twelfth month of the jihai year, the fourth of the Qianfu reign’ 千符肆年歲次已亥十二月十八日, in which the reign title probably refers to Tianfu 天福, the fourth year of which was indeed 939, a jihai year. ${ }^{303}$

On the recto, the first 17 lines of the Xiaojing (i.e. the 'Preface' and the first line of the main text) have red punctuation marks, segmenting the text into clauses and sentences. The punctuation disappears after these 17 lines, suggesting that the student who applied them was relatively familiar with the main text of the Xiaojing. Thus, technically these are not punctuation but reading marks that give evidence of a posterior engagement with the text and the manuscript, most likely by a different student. The practice of transferring manuscripts to later students is evidenced in the colophon of manuscript P.2715, which contains yet another copy of the Xiaojing. ${ }^{304}$ The colophon states that after finishing the act of copying, the student 'carefully checked it for omissions and mistakes, so that it may be handed over to later students' 點勘一無脫錯, 傳之後學. It is

302 More precisely, it corresponds to the beginning of 940, as this was the end of the year according to the lunar calendar.

303 Once again, this date would technically correspond to the beginning of 940 . My reading follows that of Zhang Yongquan 2008, v. 8, 4274, although the characters Zhang reads as 千符 are written in a scruffy hand and may represent 于時, a common formula at the beginning of dates. Nevertheless, this formula is not usually followed by numerals, which makes Zhang's reading the preferable one. See also Soymié et al. 1991, 183.

304 The colophon dates to the dinghai year. As the date is in the cyclical format, which earlier scholars associated with the Tibetan period, Ikeda 1990, 333 dates it to 807. Zhang Xiuqing 2008,13 is, however, undoubtedly correct in dating the scroll to the Guiyijun period. 
possible that the diankan 點勘 also involved punctuating it, as its first component dian 點 ('to dot, mark') seems to imply. Should this have indeed been the case, the student copying the Xiaojing would have been responsible for adding the reading marks but for the benefit of those junior students who were to use the scroll after him.

At the beginning of the verso of P.3698, the words 'student of the Lingtu Monastery' 靈圖寺斈郎 appear; unfortunately the damage makes it impossible to read the name of the student. Nevertheless, judging from the two previous Xiaojing scrolls, this bit of text was copied from the colophon on the recto. The verso contains an array of scribbles, some upside down in relation to the others, as was the case with scroll S.728. The Dunhuang Academy's updated index to the Dunhuang manuscripts sums up the content on the verso as 'circulars and miscellaneous jottings' 轉帖及雜寫. ${ }^{305}$ The analysis presented below intends to demonstrate that a careful examination of the jottings may reveal meaningful patterns in their seeming disarray.

Among the notes on the verso, is the sentence 'the ox is the powerful bodhisattva' 牛是大力菩薩, appearing on its own here, completely out of context. It uses the copula shi 是, characteristic of vernacular language, which signals that the phrase may ultimately come from a song or other non-classical text. Slightly to the left, at the bottom part of the page, the words 'the powerful bodhisattva' 大力菩薩 are repeated, again, without context. These two truncated fragments of text are unquestionably references to the popular tradition according to which the ox is a bodhisattva who took pity on humans toiling the earth and incarnated as an ox to relieve their burden. ${ }^{306}$ This is a tradition that gains momentum in the Ming-Qing period, and this note in a tenth-century Dunhuang manuscript is evidence for its early transmission.

305 Dunhuang yanjiuyuan 2000, 293.

306 See, for example, the Yuga rongi 瑜伽論記 (T:1828, 42, juan 60) by the Silla monk Dunryun 遁倫 (ca. 650-730). I am grateful for Professor Wang Yong 王勇 who drew my attention to references to this lore in Ming-Qing baojuan 寶卷 ('precious scroll') texts, such as the Huangji jiulian rutong linfan baojuan 皇极九蓮儒童臨凡寶卷 and Zhongxi cuyan baojuan 眾喜粗言寶卷. Thanks also go to Meir Shahar for kindly sharing his research on this topic. 


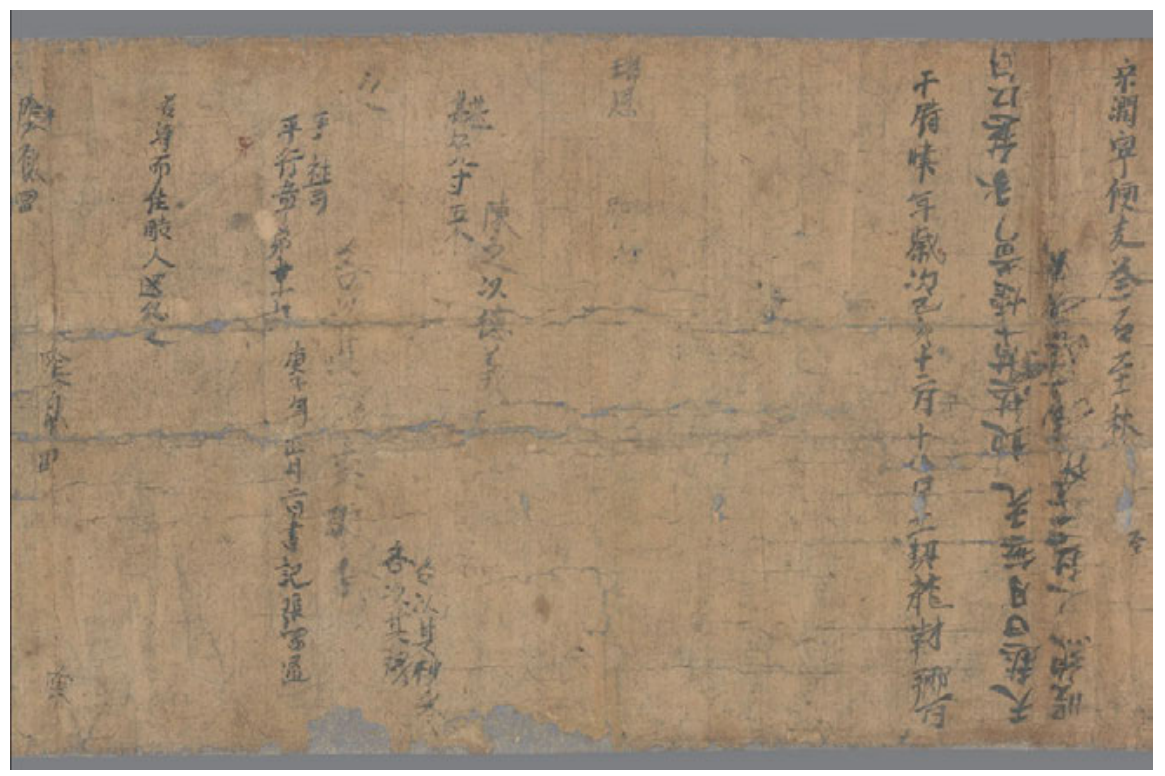

Fig. 31: Section from the verso of P.3698. $(30$ × $124.5 \mathrm{~cm}$; Bibliothèque nationale de France $)$

Further to the left, amidst other bits of textual fragments, is a quatrain starting with the words 'Heaven worries that the sun and the moon will have no light' 天 愁日月無光, shown upside-down on the right side of Fig. 31. Other bits of text, on the left half of the image, include the words 'demonstrating virtue and righteousness' 陳之以德義, which is a quote from Chapter 7 of the Xiaojing (see the recto of the scroll). ${ }^{307} \mathrm{~A}$ bit to the left, in a similar type of faded ink, we see the words 'came each according to his office to assist in the sacrifices' 各以其職來祭, a quote from Chapter 9. ${ }^{308}$ These characters occur another two times in stronger ink towards the bottom of the scroll, next to the colophon of Zhang Futong. The Xiaojing snippets are written in a hand so unskilled that without being able to link them to their source it would be very difficult, if not impossible, to decipher the characters.

307 This phrase appears in the received version of the Xiaojing as 陳之於德義 (e.g. Xiaojing zhushu 3, 2550). The version quoted on the verso of the manuscript (i.e. with the character 以 in place of 於) matches the text on the recto but also a number of early quotes of the Xiaojing in other texts; e.g. Qianfu lun 潛夫論 19, 232; Qunshu zhiyao 群書治要 10, 145.

308 I adopt, with some modification, the translation of the Xiaojing fragments from Rosemont and Ames 2009. 
Significantly, the two strings of text from the Xiaojing (i.e. 陳之以德義 on the upper part of the writing surface and 各以其職來祭 at the bottom) delineate a passage of 275 characters in length. ${ }^{309}$ The part of the Xiaojing (and the preface) before this segment is 883 , and the one after it is 1,050 characters long. It is possible that the longer segments divided further into shorter sections but there is no evidence of this in the manuscript. ${ }^{310}$ At the other end of the verso, we find the words zi yue 子曰 ('The Master said'), which, in this context, may have been a similar segment marker. Even if these words are from the Xiaojing and not some other text, their frequency makes it impossible to identify the specific location they might designate. It is likely that the text was divided into segments and the students copied or studied it in such smaller portions. At any rate, the markers delineate the Xiaojing into at least three segments. It is probably not insignificant that while the content on the verso of this scroll varies in orientation, with bits of text appearing upside down in comparison with other ones, all Xiaojing markers maintain the same alignment, evidencing a consistency that is not otherwise apparent on the verso of the scroll. In sum, we can conclude that the quotes from the Xiaojing are not random scribbles, but notation directly connected with studying the main text.

The assignment would not have always been the same length. The Xiaojing quotes on the verso of S.728, for example, divide the text differently. We find on the verso two similar markers, namely, 'the love they feel towards them is the same' 而愛同 and 'this being the case, while alive' 夫然故生, ${ }^{311}$ which break the text into three sections of 670, 356 and 1,182 characters. Comparing the manner in which the bits of texts divide the Xiaojing in manuscripts S.728 and P.3698, we find a similar pattern of a semi-long segment followed by a short one, with the final part being the longest. Fig. 32 displays this pattern in a visual form, making the similarity even more apparent.

309 This delineation is inclusive, which is clear from the fact that the first quote represents the beginning of a clause, whereas the second the end of one.

310 The first segment of 883 characters could easily divide into three segments of about 294 characters. Similarly, the last segment of 1,050 characters could break into four shorter segments of about 263 characters.

311 The section beginning with the words 'in such a world...' 夫然 is copied for a line and a half on the verso of the scroll, right next to four characters that mark its beginning. 


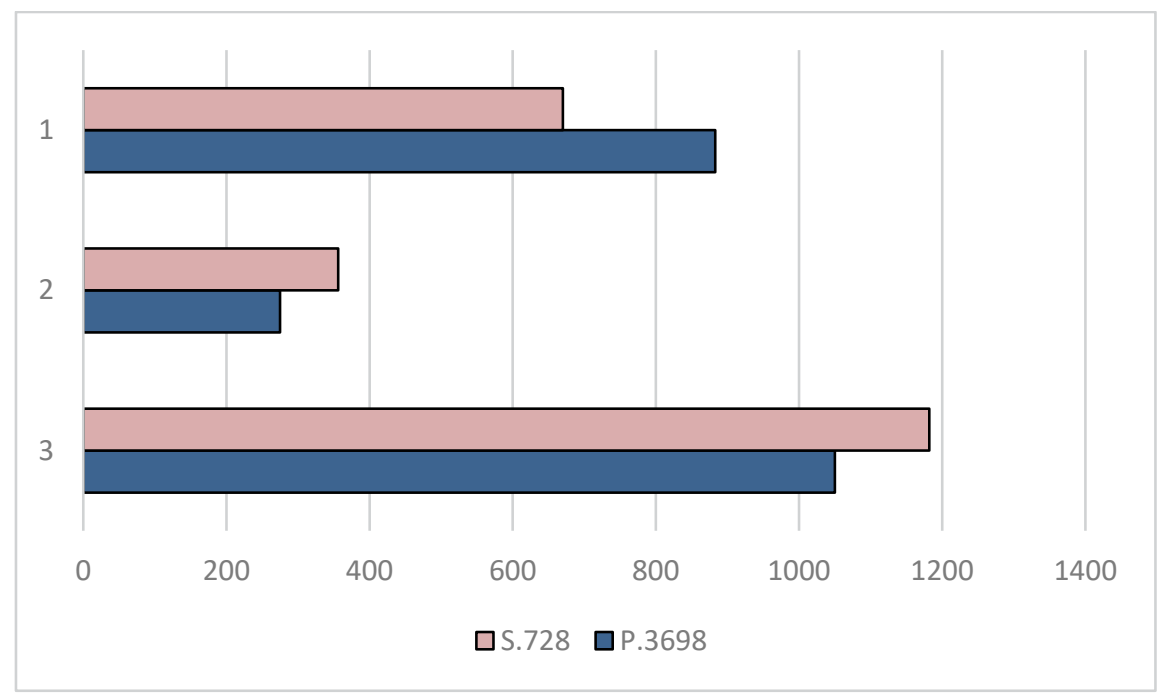

Fig. 32: The division of the Xiaojing into three segments in manuscripts S.728 and P.3698.

It is reasonable to assume that students of different age and proficiency would have had a different workload and different obligations. For example, as mentioned earlier in this chapter, manuscript S.2703, containing rows of identical characters from the Qianziwen, recorded the days spent on the exercise, allowing us to calculate the number of characters copied in the course of a single day. The student appears to have copied 12-13 lines a day, with characters ranging from 12 to 18 per line, incurring a total work load of approximately 150-230 characters per day. This was a lighter workload than the sections of the Xiaojing in manuscripts S.728 and P.3698, but it is probable that the student who wrote S.2703 was much younger. ${ }^{312}$

Another disconnected piece of text in this area of the verso of P.3698 are the words 'Conduct of Fairness, Chapter 19' 平行章第十九, which is a reference to one of the chapters of the didactic primer Baixing zhang. Further to the left are nine characters from Chapter 18 of the same text: 'If [the official] is incorruptible but unjustly cruel towards others, he will incur the people's resentment' 若清而 住(枉)酷人還怨之. Although the text itself does not appear in this manuscript, the mere presence of these small fragments is enough to demonstrate that the

312 On this and other similar student manuscripts, as well as speculations regarding the age of students, see Zürcher 1989, 36-39. See also Simson 2009, 205-207, discussing a similar exercise but using a contract. 
students who used this scroll also studied the Baixing zhang. As there are only eighteen characters between these two quotes from the text, they could not have been marking the two ends of a section intended for a single practice. They perhaps signify two separate occasions of referring to the text. The distance between the first one from the beginning of the Baixing zhang (including the title, name of author and the preface) is 1,383 characters, which is a considerably longer segment than those of the Xiaojing.

As was the case with other manuscripts of the Xiaojing discussed above, the verso of P.3698 contains a considerable amount of titles and texts. None of these is longer than one or two lines and thus they are not 'texts' per se but rather references to texts. Some of these are not referred to with a title but are merely quotes from known works (e.g. Xiaojing, Baixing zhang). Fig. 33 displays the spatial arrangement of these titles and quotes on the verso of the scroll. The boxes with dotted red borders indicate the bits that are upside down, whereas the boxes with blue solid borders, the ones right-side up. For better visibility, the notes, or their initial characters, are shown outside the borders of the manuscript.

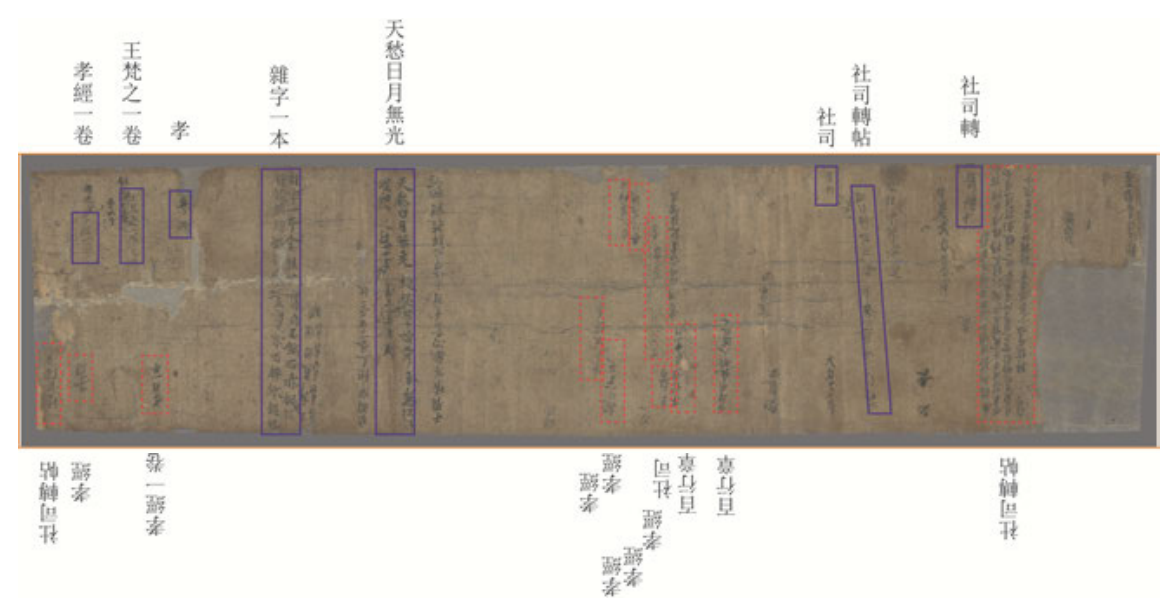

Fig. 33: The spatial arrangement of titles and quotes on the verso of manuscript P.3698.

Overall, the bits of text are in disorder, and some of them appear upside down in relation to others. It is possible, however, to identify several clusters which include texts with matching orientation and, in several cases, similar content. This pattern suggests that the items within each cluster were written around the same time but probably on a different occasion from those in other clusters. The 
titles and quotes are written in more than one hand, yet there is not enough text to arrive at a reliable conclusion regarding the number of hands. In total, it is possible to identify the following items: ${ }^{313}$

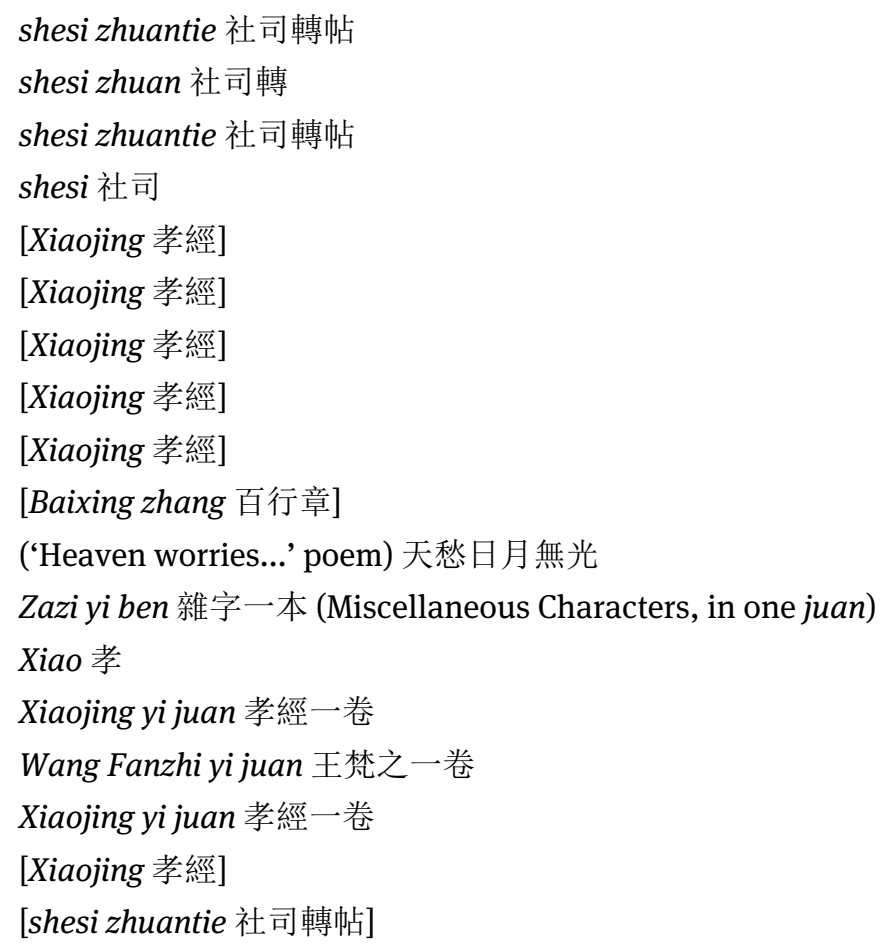

There are several instances of the heading shesi zhuantie, as well as fragments of the circulars themselves. None are complete and even the longest, written in a left-to-right direction, is but four lines long. Several fragmentary quotes from the Xiaojing seem random but, as argued above, mark sections of the text assigned to students for copying or studying. While Zazi 雜字 (Miscellaneous Characters) could be a generic reference to a category of texts or an ad hoc collections of characters intended for learning purposes, here it is followed by the words 'in one volume' 一本, indicating that it is most likely the title, perhaps abbreviated, of a specific work. Only two and a half lines of it survive here, showing that the aim was not to record it in full. ${ }^{114}$ Similarly, the title Wang Fanzhi 王梵之 is a reference

313 Square brackets indicate the items that are quotes without titles.

314 For a transcription of this fragment, see Zhang Yongquan 2008, v. 8, 4274-4273. 
to a collection of poems by Wang Fanzhi, with the last character $z h i$ 志 written as a near homophone. In sum, the texts referenced on the verso of this scroll are the Xiaojing, Zazi, Baixing zhang, the poems of Wang Fanzhi and association circulars.

Obviously, these are very similar to those on the verso of the other Xiaojing manuscripts discussed above. As a consequence, when taken together, the seemingly random scribbles on the verso of student manuscripts exhibit patterns directly related to the process of learning. The relative consistency of the patterns over the course of several decades is yet another indication of the specificity of the process and proves the scribbles, if properly interpreted, have the potential to provide additional insights into how students studied on a day-to-day level.

\subsection{Conclusions}

It stands to reason that students in Guiyijun Dunhuang, akin to students anywhere else, copied primers and works of didactic nature. The scrolls with the Xiaojing, Qianziwen, Baixing zhang and Taigong jiajiao are all examples of such activity and there is no doubt that they were copied in a school environment. Their function lay in teaching a basic set of characters and, at the same time, advocating proper conduct. In doing so, students absorbed the didactic message while acquiring literacy skills. There are dozens of examples of manuscripts featuring texts copied by students studying in local monasteries. The verso of many of these contain seemingly random scribbles and miscellaneous notes, including titles of primers, bits of information (e.g. names and dates) from the colophon on the recto, and brief fragments of pragmatic documents related to administrative and economic matters. The basic assumption forwarded in this chapter is that individually the scribble-like notes on the verso may appear to be arbitrary, but when assessed alongside similar fragmentary jottings in other manuscripts, they reveal patterns and connections that help to understand how students used the manuscripts.

In this chapter, I examined, as a case study, three Xiaojing manuscripts (S.728, S.707, P.3698) in order to assess their common traits, especially the multitude of disconnected notes on their verso. Among the findings was that some of the scribbles on the verso were directly related to the Xiaojing and the colophon on the recto. The title of the Xiaojing appeared on the verso repeatedly, as did disconnected quotes from the text itself. Additional notes referenced texts (e.g. Taigong jiajiao, Baixing zhang, Zazi) which could not be found in these manuscripts but are common in other manuscripts with student colophons. 
Presumably, the same students also studied and copied these texts, only in manuscripts that did not survive.

The presence of fragmentary bits of association circulars revealed yet another persistent pattern in the Xiaojing manuscripts. The circulars will be examined in detail in Chapter Four, here I would only like to draw attention to their significance regarding manuscripts written by students. The circular fragments can be several lines long, but in most cases consist of only a few characters. Their location on the verso appears to be random yet they occur with predictable consistency. Frequently several disconnected bits appear on the same manuscript, indicating once more that their presence is not accidental. Characteristically, they are written in an unskilled hand and contain errors and omissions. While scholars often dismiss these fragments as writing exercises, most of them are too short for such a purpose and are probably reminders of exercises expected to be completed elsewhere. A striking feature we will explore in the next chapter is that some of the circulars read from left to right, in opposite direction from how Chinese is normally written.

In all, the scribble-like notes on the verso of these scrolls cannot be viewed as random jottings, certainly not in the sense of being arbitrary. Instead, they provide evidence of students working on both the main text on the recto and other texts not present in the manuscript. Some of the notes on the verso were added by other students who may have used the manuscript years after the first student had copied the main text. The implication here is that the scrolls or booklets we see today are the product of years of collaborative engagement with the manuscript. This phenomenon is similar to that witnessed in the previous chapter regarding multiple-text manuscripts. Most importantly, as many of the students belonged to prominent families, the manuscripts must have served as tokens of a bond between the monasteries and the political elite.

The surviving evidence inevitably creates a skewed impression of the scope of education in Dunhuang. Yet the emergence of student colophons at the beginning of the Guiyijun period is not necessarily a sign of a sudden increase of the level of culture after the so-called 'dark years' of the Tibetan period. Similarly, the prevalence of monastic schools as opposed to county or commanderylevel ones does not prove that monasteries were the primary location for educational activities during this period. On the contrary, the manuscripts reveal that monasteries acted as private schools for the elite and thus were involved in the education of a relatively small number of students. 